\title{
Three-dimensional modelling of wave-induced current from the surf zone to the inner shelf
}

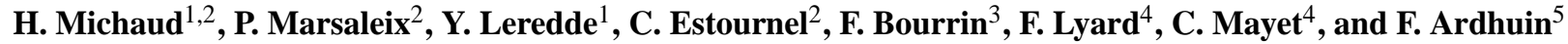 \\ ${ }^{1}$ Géosciences Montpellier, UMR5243, CNRS - Université Montpellier 2 Sciences et Techniques, place E Bataillon, \\ 34095 Montpellier cedex 5, France \\ ${ }^{2}$ Laboratoire d'Aérologie,UMR5560, CNRS - Université de Toulouse, 14 avenue Edouard Belin, 31400 Toulouse, France \\ ${ }^{3}$ Centre de Formation et de Recherche sur l'Environnement Marin, UMR5110, CNRS - Université de Perpignan Via Domitia, \\ 52 avenue de Villeneuve, 66860 Perpignan cedex, France \\ ${ }^{4}$ Laboratoire d'Etudes en Géophysique et Océanographie Spatiales (CNRS/CNES/IRD/UPS), 14 avenue Edouard Belin, \\ 31400 Toulouse, France \\ ${ }^{5}$ IFREMER, Centre de Brest, Laboratoire d'Océanographie Spatiale, 29280 Plouzané, France
}

Correspondence to: H. Michaud (michaud.heloise@gmail.com)

Received: 13 October 2011 - Published in Ocean Sci. Discuss.: 9 December 2011

Revised: 5 July 2012 - Accepted: 19 July 2012 - Published: 17 August 2012

\begin{abstract}
We develop and implement a new method to take into account the impact of waves into the 3-D circulation model SYMPHONIE (Marsaleix et al., 2008, 2009a) following the simplified equations of Bennis et al. (2011), which use glm2z-RANS theory (Ardhuin et al., 2008c). These adiabatic equations are completed by additional parameterizations of wave breaking, bottom friction and wave-enhanced vertical mixing, making the forcing valid from the surf zone through to the open ocean. The wave forcing is performed by wave generation and propagation models WAVEWATCH III $^{\circledR}$ (Tolman, 2008, 2009; Ardhuin et al., 2010) and SWAN (Booij et al., 1999). The model is tested and compared with other models for a plane beach test case, previously tested by Haas and Warner (2009) and Uchiyama et al. (2010). A comparison is also made with the laboratory measurements of Haller et al. (2002) of a barred beach with channels. Results fit with previous simulations performed by other models and with available observational data.

Finally, a realistic case is simulated with energetic waves travelling over a coast of the Gulf of Lion (in the northwest of the Mediterranean Sea) for which currents are available at different depths as well as an accurate bathymetric database of the 0-10 m depth range. A grid nesting approach is used to account for the different forcings acting at different spatial scales. The simulation coupling the effects of waves and currents is successful to reproduce the powerful northward
\end{abstract}

littoral drift in the $0-15 \mathrm{~m}$ depth zone. More precisely, two distinct cases are identified: When waves have a normal angle of incidence with the coast, they are responsible for complex circulation cells and rip currents in the surf zone, and when they travel obliquely, they generate a northward littoral drift. These features are more complicated than in the test cases, due to the complex bathymetry and the consideration of wind and non-stationary processes. Wave impacts in the inner shelf are less visible since wind and regional circulation seem to be the predominant forcings. Besides, a discrepancy between model and observations is noted at that scale, possibly linked to an underestimation of the wind stress.

This three-dimensional method allows a good representation of vertical current profiles and permits the calculation of the shear stress associated with waves and currents. Future work will focus on the combination with a sediment transport model.

\section{Introduction}

Over the past half-century, considerable advances have been made in the field of numerical modelling of coastal hydrodynamics, with major efforts made to take wave-current interactions into account. Such studies have allowed the investigation of beach protection, contaminant monitoring, 
navigational issues, coastal management and prediction of hazardous zones for swimmers. A wide variety of modelling techniques have been applied to the surf zone, based on depth-integrated equations. These include phase resolving (e.g. Chen et al., 2003; Clark et al., 2011), group-averaged (Reniers et al., 2004), or fully phase-averaged. These models are unfortunately not well adapted for continental shelf processes, which are influenced by stratification, making it difficult to model cross-shore transport phenomena uniformly from the beach to the shelf break. Recently, developed 3-D wave-current interaction theories (e.g. Mellor, 2003; McWilliams et al., 2004; Ardhuin et al., 2008c) may provide useful approaches for this problem.

Following the pioneering modelling work by Rascle (2007); Newberger and Allen (2007); Uchiyama et al. (2010), we investigate the influence of surface waves on ocean circulation in the inner shelf and surf zone. The main influences of waves on currents occur through bottom (e.g. Komar et al., 1972) and surface stresses (e.g. Donelan et al., 1993), while turbulent kinetic energy at the surface is enhanced by wave breaking (e.g. Agrawal et al., 1992). Waves are associated with mean momentum that can be observed as a surface-intensified drift velocity (Stokes, 1847). In deep water, this drift is highly correlated with the wind speed and wave height, with a magnitude of the order $6 \times 10^{-4} U_{10}^{2}$ where $U_{10}$, the $10 \mathrm{~m}$ wind speed, is in $\mathrm{m} \mathrm{s}^{-1}$ (Ardhuin et al., 2009). In the surf zone, the drift is not correlated with wind speed and can reach as much as $30 \%$ of the phase speed, with a strong surface intensification (Ardhuin et al., 2008c). The actual drift of water particles is the sum of this Stokes drift and the Eulerian current, with wave influences also on the Eulerian current (e.g. Xu and Bowen, 1994). Reciprocally, currents can modify waves by, refraction, partial reflection, up to blocking (Smith, 1975; Chawla and Kirby, 2002).

A first approach to the study of wave/current interactions can be to add certain effects in particular contexts (e.g. Jordà et al., 2007). For example, Mastenbroek et al. (1993) improve their numerical simulations of storm surges by introducing a wave-dependent drag coefficient for the wind.

During the 1960s, Taylor (1962) and Whitham (1962) focused on non-linear wave properties. These works then led to the radiation stress theory, which was first introduced by Longuet-Higgins and Stewart (1962), and then by Phillips (1977). This theory takes into account the excess flow of momentum due to the presence of waves in the barotropic momentum equations for the total current, thanks to the addition of radiation stress gradients. In radiation stress theory, wave and current momenta are combined and the effect of the waves is applied to this total momentum. Although this is practical for depth-integrated flows, it becomes a problem in 3-D models, in particular because the Stokes drift is not mixed and is often the main source of vertical shear near the surface, with important consequences for surface drift (e.g. Rascle and Ardhuin, 2009). Instead, the problem can be for- mulated for the current momentum only, as shown by Garrett (1976) for depth-integrated equations, and Andrews and McIntyre (1978) in the most general form. Several theories have been developed and applied for the full momentum (involving radiation stresses) or the current momentum only (in which a vortex force appears). Although much work is still to be developed for the proper treatment of turbulence in the presence of waves, several papers have established that all published theories that use radiation stresses have some errors at the leading order, which may cause spurious circulations (Ardhuin et al., 2008b; Kumar et al., 2011; Bennis and Ardhuin, 2011).

Here we shall use a formulation of the "current momentum", which is formally defined as the quasi-Eulerian momentum (Andrews and McIntyre, 1978; Jenkins, 1989), namely the Lagrangian mean velocity minus the Stokes drift. Here we use an approximation of the exact equations from (Andrews and McIntyre, 1978) to second order in wave slope, including a transformation to cartesian coordinates (glm2-z approximation, Ardhuin et al., 2008c), in a simplified form that neglects the vertical current shear effect on the dynamic pressure (Bennis et al., 2011). In the limit of weak vertical current shear, these equations are formally equivalent to the Eulerian-mean equations of McWilliams et al. (2004) that are based on an analytic continuation across the air-sea interface, and which have been used by Uchiyama et al. (2010).

Previous studies dealing with wave-current interaction are often focused on the surf zone (with water depths on the order of $1 \mathrm{~m}$ ) (e.g. Uchiyama et al., 2010; Haas and Warner, 2009; Weir et al., 2011). Few studies and measurements have been dedicated to the mid-shelf zone (with water depths of order $100 \mathrm{~m}$ ), or at least to the inner shelf (between the surf zone and mid shelf): Lentz et al. $(1999,2008)$ were one of the first to study the influence of waves on the inner shelf. The purpose of this article is to extend the study of wave-current interaction to both the inner shelf and the open ocean by implementing the new set of equations of Bennis et al. (2011) in the primitive equation model SYMPHONIE (Marsaleix et al., 2008). By using a nested strategy, which allows studies at all scales and by completing the model with additional parameterizations of wave breaking, bottom friction and waveenhanced vertical mixing, we ensure that the forcing is valid from the surf zone through to the open ocean. We test and compare our model to measurements made on the Têt inner shelf during a typical winter storm. This inner shelf has a bathymetry made up of complex sandbar systems, therefore before tackling this real case, the accuracy of the model is first assessed in two idealized test cases.

Wave and circulation models, modified with the formulation of Bennis et al. (2011), are presented in Sect. 2. Section 3 describes two academic test cases of the surf zone. The first is on an idealized plane beach submitted to obliquely incident spectral waves (a case also tested by Haas and Warner, 2009, and Uchiyama et al., 2010). The second case tests the 
ability of the model to correctly reproduce rip currents generated by a barred beach, by simulating the test $\mathrm{B}$ experiment of Haller et al., 2002). Section 4 focuses on the 21 February 2004 storm in the Têt inner shelf. The simulated currents are compared to the observed ones to assess model accuracy. Finally, Sect. 5 provides a summary and conclusion.

\section{Models}

\subsection{Coastal circulation model}

We used the Boussinesq hydrostatic circulation ocean model described in Marsaleix et al. (2008, 2009a,b). Components of currents, temperature and salinity are computed on a Cgrid using an energy-conserving finite-difference method. A generalized sigma coordinate (Ulses et al., 2008c) is used in order to refine resolution near the bottom and the surface. A complete description of the bulk formulae used to compute the air/sea fluxes is given in Estournel et al. (2009). The so called SYMPHONIE model has been extensively used in studies of the Mediterranean Sea, mostly at the scale of continental shelves (Ulses, 2005; Estournel et al., 2003, 2005), generally comparing satisfactorily with available in-situ observations. Leredde and Michaud (2008) however found that the model did not perform that well for the case of an extreme meteorological event reported in the Gulf of Lion in February 2007. It was concluded that the relative failure of the simulations was likely a consequence of the lack of a proper wave/current parameterization. This study incited the present one, in which we implement this particular development in our model, following the method proposed by Bennis et al. (2011).

\subsubsection{General equations}

The momentum equations of the coastal circulation model are rewritten in order to take into account the wave forcing. This gives the Eqs. (18)-(21) of Bennis et al. (2011) which govern the evolution of the quasi-Eulerian velocities $(\hat{u}, \hat{v}, \hat{w})$ equal to

$$
(\hat{u}, \hat{v}, \hat{w})=(u, v, w)-\left(U_{\mathrm{s}}, V_{\mathrm{s}}, W_{\mathrm{s}}\right)
$$

where $(u, v, w)$ are the mean Lagrangian velocities and $\left(U_{\mathrm{s}}, V_{\mathrm{s}}, W_{\mathrm{s}}\right)$ the Stokes drift in the horizontal (x-, y-) and vertical (z-) directions. They are valid from the bottom $z=-h$ to the local phase-averaged free surface $z=\hat{\eta}$.

$$
\begin{array}{r}
\frac{\partial \hat{u}}{\partial t}+\hat{u} \frac{\partial \hat{u}}{\partial x}+\hat{v} \frac{\partial \hat{u}}{\partial y}+\hat{w} \frac{\partial \hat{u}}{\partial z}-f \hat{v}+\frac{1}{\rho} \frac{\partial p^{\mathrm{H}}}{\partial x}= \\
{\left[f+\left(\frac{\partial \hat{v}}{\partial x}-\frac{\partial \hat{u}}{\partial y}\right)\right] V_{\mathrm{s}}-W_{\mathrm{s}} \frac{\partial \hat{u}}{\partial z}-\frac{\partial J}{\partial x}+F_{\mathrm{m}, \mathrm{x}}+F_{\mathrm{d}, \mathrm{x}}}
\end{array}
$$

$$
\begin{array}{r}
\frac{\partial \hat{v}}{\partial t}+\hat{u} \frac{\partial \hat{v}}{\partial x}+\hat{v} \frac{\partial \hat{v}}{\partial y}+\hat{w} \frac{\partial \hat{v}}{\partial z}+f \hat{u}+\frac{1}{\rho} \frac{\partial p^{\mathrm{H}}}{\partial y}= \\
-\left[f+\left(\frac{\partial \hat{v}}{\partial x}-\frac{\partial \hat{u}}{\partial y}\right)\right] U_{\mathrm{s}}-W_{\mathrm{s}} \frac{\partial \hat{v}}{\partial z}-\frac{\partial J}{\partial y}+F_{\mathrm{m}, \mathrm{y}}+F_{\mathrm{d}, \mathrm{y}}
\end{array}
$$

with $p^{\mathrm{H}}$ the hydrostatic pressure, $f$ the Coriolis parameter, $\rho$ the mean density and $t$ the time. The forces added by the wave forcing in the momentum equations are

- the vortex force: $\left(\left[\frac{\partial \hat{v}}{\partial x}-\frac{\partial \hat{u}}{\partial y}\right] V_{\mathrm{s}}-W_{\mathrm{s}} \frac{\partial \hat{u}}{\partial z},\left[\frac{\partial \hat{v}}{\partial x}-\frac{\partial \hat{u}}{\partial y}\right] U_{\mathrm{s}}-\right.$ $\left.W_{\mathrm{s}} \frac{\partial \hat{v}}{\partial z}\right)$

- the Stokes-Coriolis force: $\left(f V_{\mathrm{s}},-f U_{\mathrm{s}}\right)$

- the force linked to the wave-induced mean pressure $J$ called the Bernoulli pressure head: $\left(-\frac{\partial J}{\partial x},-\frac{\partial J}{\partial y}\right)$

- the mixing force where some parameterizations of the wave-enhanced mixing are taken into account: $\left(F_{\mathrm{m}, \mathrm{x}}, F_{\mathrm{m}, \mathrm{y}}\right)$

- the force of dissipation by breaking, bottom dissipation and wave-turbulence interaction: $\left(F_{\mathrm{d}, \mathrm{x}}, F_{\mathrm{d}, \mathrm{y}}\right)$

The evolution of $C$, the concentration of a passive tracer, is then governed by

$\frac{\partial C}{\partial t}+\frac{\partial u C}{\partial x}+\frac{\partial v C}{\partial y}+\frac{\partial w C}{\partial z}=0$,

and the mass conservation becomes

$\frac{\partial u}{\partial x}+\frac{\partial v}{\partial y}+\frac{\partial w}{\partial z}=0$.

These equations were implemented in the MARS 3-D model (Lazure and Dumas, 2008). We transform them into a discrete form by using the flux-divergence form of the advection terms which can be found in most coastal hydrodynamic models (e.g. Marsaleix et al., 2008; Blumberg and Mellor, 1987; Shchepetkin and McWilliams, 2005) (see Appendix A). In addition, the Eqs. (2)-(3) taken from Bennis et al. (2011) neglected the effect of the vertical current shear. In realistic settings, a strong vertical shear can occur, so nontrivial higher-order Bernoulli head terms must be considered. Equations then become

$$
\begin{gathered}
\frac{\partial \hat{u}}{\partial t}+\frac{\partial u \hat{u}}{\partial x}+\frac{\partial v \hat{u}}{\partial y}+\frac{\partial w \hat{u}}{\partial z}-f \hat{v}+\frac{1}{\rho} \frac{\partial p^{\mathrm{H}}}{\partial x}=f V_{\mathrm{s}} \\
+\frac{\partial \hat{u}}{\partial x} U_{\mathrm{s}}+\frac{\partial \hat{v}}{\partial x} V_{\mathrm{s}}-\frac{\partial\left(S^{\mathrm{J}}+S^{\text {shear }}\right)}{\partial x}+F_{\mathrm{m}, \mathrm{x}}+F_{\mathrm{d}, \mathrm{x}} \\
\frac{\partial \hat{v}}{\partial t}+\frac{\partial u \hat{v}}{\partial x}+\frac{\partial v \hat{v}}{\partial y}+\frac{\partial w \hat{v}}{\partial z}+f \hat{u}+\frac{1}{\rho} \frac{\partial p^{\mathrm{H}}}{\partial y}=-f U_{\mathrm{s}} \\
+\frac{\partial \hat{u}}{\partial y} U_{\mathrm{s}}+\frac{\partial \hat{v}}{\partial y} V_{\mathrm{s}}-\frac{\partial\left(S^{\mathrm{J}}+S^{\text {shear }}\right)}{\partial y}+F_{\mathrm{m}, \mathrm{y}}+F_{\mathrm{d}, \mathrm{y}} .
\end{gathered}
$$

This choice allows a global calculation of the term $w=$ $\hat{w}+W_{\mathrm{s}}$ and the calculation of the value $W_{\mathrm{s}}$ is no longer 
needed. In the new set of equations, the vortex force does not appear clearly and is replaced by a new force equal to $\frac{\partial \hat{u}}{\partial x} U_{\mathrm{s}}+\frac{\partial \hat{v}}{\partial x} V_{\mathrm{s}}, \frac{\partial \hat{u}}{\partial y} U_{\mathrm{s}}+\frac{\partial \hat{v}}{\partial y} V_{\mathrm{s}}$. But we note that we can get back to the usual vortex force provided that the Stokes current contribution to the advection terms, namely, $\left(\frac{\partial U_{\mathrm{s}} \hat{u}}{\partial x}+\frac{\partial V_{\mathrm{s}} \hat{u}}{\partial y}+\right.$ $\left.\frac{\partial W_{\mathrm{s}} \hat{u}}{\partial z}, \frac{\partial U_{\mathrm{s}} \hat{v}}{\partial x}+\frac{\partial V_{\mathrm{s}} \hat{v}}{\partial y}+\frac{\partial W_{\mathrm{s}} \hat{v}}{\partial z}\right)$, is taken into account.

The wave-induced pressure $J$ in Eqs. (2) and (3) is thus replaced by a wave-induced pressure term $S^{\mathrm{J}}$ and a shearinduced pressure term $S^{\text {shear }}$. The depth uniform waveinduced term $S^{\mathrm{J}}$ is equal to

$S^{\mathrm{J}}=g \frac{k E}{\sinh (2 k D)}$

with $D=\eta+h$ the water depth, $g$ the acceleration due to gravity, $E$ the wave energy and $k$ the wave number. The shear-induced term is given in Eq. (40) of Ardhuin et al. (2008c), using a wave spectrum integrated form. Here, it has been replaced by a spectrum-averaged expression around the principal frequency, i.e.

$S^{\text {shear }}=S_{\text {hom }}^{\text {shear }}+S_{\text {cis }}^{\text {shear }}$

with

$$
\begin{array}{r}
S_{\text {hom }}^{\text {shear }}=-E\left[\frac{\sigma}{k} \tanh (k D)\left(k_{\mathrm{x}}\left(\frac{\partial \hat{u}}{\partial z}\right)^{z=\hat{\eta}}+k_{\mathrm{y}}\left(\frac{\partial \hat{v}}{\partial z}\right)^{z=\hat{\eta}}\right)\right. \\
\left.+\frac{1}{2}\left(k_{\mathrm{x}}\left(\frac{\partial \hat{u}}{\partial z}\right)^{z=\hat{\eta}}+k_{\mathrm{y}}\left(\frac{\partial \hat{v}}{\partial z}\right)^{z=\hat{\eta}}\right)^{2}\right]
\end{array}
$$

$$
\begin{array}{r}
S_{\mathrm{cis}}^{\text {shear }}=\int_{\mathrm{z}}^{\hat{\eta}}\left[W_{\mathrm{s}}\left(\frac{\partial U_{\mathrm{s}}}{\partial x}+\frac{\partial V_{\mathrm{s}}}{\partial y}\right)-U_{\mathrm{s}} \frac{\partial \hat{u}+U_{\mathrm{s}}}{\partial z^{\prime}}\right. \\
\left.-V_{\mathrm{s}} \frac{\partial \hat{v}+V_{\mathrm{s}}}{\partial z^{\prime}}\right] d z^{\prime} .
\end{array}
$$

The 3-D Stokes velocities being non-divergent (Uchiyama et al., 2010), we have (Bennis et al., 2011) (Eq. 18):

$\frac{\partial U_{\mathrm{s}}}{\partial x}+\frac{\partial V_{\mathrm{s}}}{\partial y}=-\frac{\partial W_{\mathrm{s}}}{\partial z}$.

This leads to

$$
\begin{array}{r}
S_{\text {cis }}^{\text {shear }}=-\int_{\mathrm{z}}^{\hat{\eta}}\left[\frac{1}{2} \frac{\partial}{\partial z^{\prime}}\left(U_{\mathrm{s}}^{2}+V_{\mathrm{s}}^{2}+W_{\mathrm{s}}^{2}\right)\right. \\
\left.+U_{\mathrm{s}} \frac{\partial \hat{u}}{\partial z^{\prime}}+V_{\mathrm{s}} \frac{\partial \hat{v}}{\partial z^{\prime}}\right] d z^{\prime} .
\end{array}
$$

Assuming that $U_{\mathrm{s}}^{2}+V_{\mathrm{s}}^{2}>>W_{\mathrm{s}}^{2}$, the vertical velocity dependent terms are consequently omitted in our calculus.

Stokes velocities are given by

$$
\left\{\begin{array}{l}
\left(U_{\mathrm{s}}, V_{\mathrm{s}}\right)=\sigma k(\cos \theta, \sin \theta) E \frac{2 \cdot \cosh (2 k(z+h))}{\cosh (2 k D)} \\
\text { in shallow waters for } k D<6 \\
\text { and }\left(U_{\mathrm{s}}, V_{\mathrm{s}}\right)=\sigma k(\cos \theta, \sin \theta) E 2 e^{2 \cdot k(z-\eta)} \\
\text { in deep waters for } k D>6
\end{array}\right.
$$

with $\sigma$ the relative frequency and $\theta$ the angle of wave propagation.

In realistic configurations (i.e. for random waves), we replace $E$ by the elementary variance $E(\theta, \sigma) d \theta d \sigma$ and we integrate the entire expression over the spectrum of the relative frequencies and angles of wave propagation of the wave model. The WAVEWATCH III wave model, hereinafter WW3 (version 4.04-SHOM; Tolman, 2008, 2009; Ardhuin et al., 2010), provides directly the wave-induced pressure $S^{\mathrm{J}}$ and the surface Stokes velocities $\left(\left(U_{\mathrm{sf}}\left(k_{\mathrm{n}}\right), V_{\mathrm{sf}}\left(k_{\mathrm{n}}\right)=\right.\right.$ $\left.w_{\mathrm{n}} k_{\mathrm{n}} E\right)$ discretized in the frequency spectrum, so the Stokes drift can be calculated by summing these terms over the frequency spectrum:

$\left(U_{\mathrm{s}}, V_{\mathrm{s}}\right)=\sum_{k_{\mathrm{n}}}\left(U_{\mathrm{sf}}\left(k_{\mathrm{n}}\right), V_{\mathrm{sf}}\left(k_{\mathrm{n}}\right)\right) P\left(z ; k_{\mathrm{n}}\right)$

with $k_{\mathrm{n}}$ the wave numbers associated to the different frequencies of the spectrum. $w_{\mathrm{n}}$ are calculated by $w_{\mathrm{n}}=$ $\sqrt{g k_{\mathrm{n}} \tanh \left(k_{\mathrm{n}} D\right)}$ and $P\left(z ; k_{\mathrm{n}}\right)$, the vertical profiles associated with the different frequencies, are defined by

$$
\left\{\begin{array}{l}
P\left(z ; k_{\mathrm{n}}\right)=\frac{2 \cdot \cosh \left(2 k_{\mathrm{n}}(z+h)\right)}{\cosh \left(2 k_{\mathrm{n}} D\right)} \text { in shallow waters for } k_{\mathrm{n}} D<6 \\
P\left(z ; k_{\mathrm{n}}\right)=2 e^{2 \cdot k_{n}(z-\eta)} \text { in deep waters for } k_{\mathrm{n}} D>6
\end{array}\right.
$$

Stokes drift is strongly sheared at the surface so a high resolution near the surface is required.

In these equations, the wave-induced dissipation force as defined by Bennis et al. (2011) is split into two forces: one associated with wave-breaking dissipation (bathymetric breaking and whitecapping), and one induced by bottom dissipation, $\boldsymbol{F}_{\mathrm{d}}=\boldsymbol{F}_{\mathrm{d}}^{\text {surf }}+\boldsymbol{F}_{\mathrm{d}}^{\text {bot }}$. In the absence of a known vertical profile, these two forces find themselves in the boundary conditions respectively at the surface and at the bottom as surface and bottom stresses. One can thus impose an empirical vertical profile for the two forces (Bennis et al., 2011; Uchiyama et al., 2010). On the other hand, the vertical profile of velocity is possibly not really sensitive to such issues because of the smoothing effects induced by strong vertical mixing (Rascle et al., 2006). In our case, we have chosen to consider the force associated to the bottom dissipation as a bottom stress and to impose a vertical distribution function for the force associated with wave-breaking dissipation:

$$
\boldsymbol{F}_{\mathrm{d}}^{\mathrm{surf}}=\frac{\boldsymbol{\tau}_{\mathrm{wo}}}{\rho} \frac{\cosh \left(\frac{z+h}{1.6 \kappa H_{\mathrm{sw}}}\right)}{\int_{-h}^{\hat{\eta}} \cosh \left(\frac{z+h}{1.6 \kappa H_{\mathrm{sw}}}\right) d z}
$$

where $\kappa=0.4$ is the Von Karman constant; $\boldsymbol{\tau}_{\mathrm{wo}}=$ $\left(\tau_{\mathrm{wo}, \mathrm{x}}, \tau_{\mathrm{wo}, \mathrm{y}}\right)$ is the momentum flux from wave to ocean linked to wave breaking (bathymetric breaking, or whitecapping); wave-turbulence interaction and viscous effects and $H_{\text {sw }}$ is the significant wave height of the wind-sea only. $\boldsymbol{\tau}_{\text {wo }}$ and $H_{\mathrm{sw}}$ are provided by WW3. For monochromatic waves, we link $\boldsymbol{\tau}_{\text {wo }}$ to the wave dissipation due to wave breaking $\epsilon^{\mathrm{b}}$ 
used by Uchiyama et al. (2010), by

$$
\boldsymbol{\tau}_{\mathrm{wo}}=\frac{\epsilon^{\mathrm{b}} \boldsymbol{k}}{\sigma}
$$

In fact, this ratio is often used in the literature, and given as a $\frac{1}{\rho g}$ factor by the Simulating WAves Nearshore wave model (SWAN-version 40.72; Booij et al., 1999).

\subsubsection{Boundary conditions}

Boundary conditions then become

- At the surface:

$\left\{\begin{array}{l}\left.K_{\mathrm{z}} \frac{\partial \hat{u}}{\partial z}\right|_{z=\hat{\eta}}=\tau_{\mathrm{a}, \mathrm{x}}-\tau_{\mathrm{aw}, \mathrm{x}} \\ \left.K_{\mathrm{z}} \frac{\partial \hat{v}}{\partial z}\right|_{z=\hat{\eta}}=\tau_{\mathrm{a}, \mathrm{y}}-\tau_{\mathrm{aw}, \mathrm{y}}\end{array}\right.$

with $K_{\mathrm{Z}}$ the vertical eddy viscosity calculated by a turbulent closure scheme representing the energy cascade towards small scales. $\tau_{\mathrm{a}}=\left(\tau_{\mathrm{a}, \mathrm{x}}, \tau_{\mathrm{a}, \mathrm{y}}\right)$ the wind stress and $\tau_{\mathrm{aw}}=\left(\tau_{\mathrm{aw}, \mathrm{x}}, \tau_{\mathrm{aw}, \mathrm{y}}\right)$ the momentum flux from atmosphere to wave. In fact, waves influence the flux transfers from atmosphere to ocean. A part of the atmosphere momentum flux goes directly in the ocean via $\boldsymbol{\tau}_{\mathrm{a}}$. Another part $\boldsymbol{\tau}_{\mathrm{aw}}$ goes into the wave field. Then this field is subjected to dissipation and releases $\boldsymbol{\tau}_{\text {wo }}$. At a larger scale than the surf zone, $\boldsymbol{\tau}_{\text {aw }}$ and $\boldsymbol{\tau}_{\mathrm{wo}}$ tend to cancel each other. Actually, only a small part of $\boldsymbol{\tau}_{\mathrm{aw}}(5 \%)$ is radiated into the wave field (Ardhuin et al., 2004). WW3 provides directly $\boldsymbol{\tau}_{\text {aw }}$. In the surf zone, the term $\boldsymbol{\tau}_{\text {wo }}$ is predominant, and $\boldsymbol{\tau}_{\mathrm{aw}}$ is neglected.

\section{- On the bottom:}

We add the momentum lost by waves due to bottom friction $\boldsymbol{\tau}_{\mathrm{wob}}$ in the bottom boundary condition of the momentum equation. Adding this wave dissipation rate permits the reproduction of the bottom streaming flow, that has the same direction as the waves.

$$
\left\{\begin{array}{l}
\left.K_{\mathrm{z}} \frac{\partial \hat{u}}{\partial z}\right|_{z=-h}=\tau_{\mathrm{bot}, \mathrm{x}}+\tau_{\mathrm{wob}, \mathrm{x}} \\
\left.K_{\mathrm{z}} \frac{\partial \hat{v}}{\partial z}\right|_{z=-h}=\tau_{\mathrm{bot}, \mathrm{y}}+\tau_{\mathrm{wob}, \mathrm{y}}
\end{array}\right.
$$

$\boldsymbol{\tau}_{\text {bot }}=\left(\tau_{\text {bot, } \mathrm{x}}, \tau_{\text {bot, } \mathrm{y}}\right)$ is the bottom stress linked to current. We consider two different parameterizations for this term. The first one is a quadratic bottom drag parameterization and is only linked to the current through

$\boldsymbol{\tau}_{\text {bot }}=\boldsymbol{\tau}_{\mathrm{c}}=\rho C_{\mathrm{d}}\left\|\boldsymbol{V}_{\mathrm{b}}\right\| \boldsymbol{V}_{\mathrm{b}}$

with $C_{\mathrm{d}}$ the drag coefficient and $\boldsymbol{V}_{\mathrm{b}}$ the near bottom current.

The second parameterization is a drag law function linked to waves and currents, established by Soulsby et al. (1995):

$\boldsymbol{\tau}_{\text {bot }}=\boldsymbol{\tau}_{\mathrm{c}}\left[1+1.2\left(\frac{\left|\tau_{\mathrm{w}}\right|}{\left|\tau_{\mathrm{w}}\right|+\left|\boldsymbol{\tau}_{\mathrm{c}}\right|}\right)^{3.2}\right]$

with $\boldsymbol{\tau}_{\mathrm{c}}$ the bottom stress due to current only, equal to

$\boldsymbol{\tau}_{\mathrm{c}}=\rho\left[\frac{\kappa}{\ln \left(z_{1} / z_{0}\right)}\right]^{2}\left\|\boldsymbol{V}_{\mathrm{b}}\right\| \boldsymbol{V}_{\mathrm{b}}$ where $z_{0}$ is a length scale representing the roughness of the boundary (here the bottom boundary) and $z_{1}$ is the distance between the first level above the bottom boundary and the bottom boundary. $\tau_{\mathrm{w}}$ is the bottom stress linked to waves only, given by

$\left|\tau_{\mathrm{w}}\right|=0.5 \rho f_{\mathrm{w}}\left|\boldsymbol{u}_{\text {orb }}\right|^{2}$.

In the following, depending on the case, we will use Eq. (21) (Sects. 3.1 and 3.2) or Eq. (22) (Sect. 4).

The momentum lost by waves due to bottom friction is given by

$\boldsymbol{\tau}_{\mathrm{wob}}=\frac{\epsilon^{\mathrm{wd}} \boldsymbol{k}}{\sigma}$

with $\epsilon^{\mathrm{wd}}$ the wave bottom drag calculated using the parameterization of Reniers et al. (2004): $\epsilon^{\mathrm{wd}}=\frac{1}{2 \sqrt{\pi}} \rho f_{\mathrm{w}}\left|\boldsymbol{u}_{\mathrm{orb}}\right|^{3}$, $\boldsymbol{u}_{\text {orb }}$ the bottom wave orbital velocity calculated by

$\left|\boldsymbol{u}_{\mathrm{orb}}\right|=\frac{\sigma H_{\mathrm{s}}}{\sqrt{8 \sinh (k D)}}$

and $f_{\mathrm{w}}$ the wave friction factor given by Myrhaug et al. (2001):

$\left\{\begin{array}{l}f_{\mathrm{w}}=1.39\left(\frac{a_{\mathrm{bw}}}{z_{0}}\right)^{-0.52} \quad \text { if } \quad 200<\frac{a_{\mathrm{bw}}}{z_{0}}<11000 \\ f_{\mathrm{w}}=18\left(\frac{a_{\mathrm{bw}}}{z_{0}}\right)^{-1} \quad \text { if } \quad \frac{a_{\mathrm{bw}}}{z_{0}}<200 \\ f_{\mathrm{w}}=0.112\left(\frac{a_{\mathrm{bw}}}{z_{0}}\right)^{-0.25} \quad \text { if } \quad 11000<\frac{a_{\mathrm{bw}}}{z_{0}}\end{array}\right.$

with $z_{0}$ the bottom roughness length and $a_{\mathrm{bw}}$ the half orbital excursion length given by $a_{\mathrm{bw}}=\frac{\left|u_{\mathrm{orb}}\right| T}{2 \pi}$ (with $T$ the wave period).

\section{- Lateral boundaries:}

At the open boundaries, for realistic simulations, radiation conditions from Flather (1976) are applied. Technically, we follow the Eqs. (14) of Marsaleix et al. (2006). Thus, for the sea surface elevation external variable:

$\eta=\eta_{\mathrm{F}} \pm \sqrt{\frac{D}{g}\left(\hat{u}^{\mathrm{N}}-u_{\mathrm{F}}^{\mathrm{N}}\right)}$

where $\hat{u}^{\mathrm{N}}$ is the velocity normal to the boundary, and "F" refers to the external forcing term. If waves are the only external forcing:

$\left\{\begin{array}{l}\eta_{\mathrm{F}}=-\frac{S^{\mathrm{J}}+S_{\text {hom }}^{\text {shear }}}{g} \\ u_{\mathrm{F}}^{\mathrm{N}}=-U_{\mathrm{s}}^{N} .\end{array}\right.$

Boundary conditions (Eq. 29) are deduced from the momentum equation (Eqs. 2 and 3 ) and some simplifying hypotheses (steady solution, non linear terms are neglected).

\subsubsection{Wave-induced vertical mixing}

Vertical mixing is parameterized according to the $k-\epsilon$ turbulent closure scheme. The vertical eddy viscosity $K_{\mathrm{z}}$ is calculated by: $K_{\mathrm{z}}=\sqrt{2 E_{\mathrm{k}}} l_{\mathrm{k}} S_{\mathrm{z}}$ and the eddy diffusivity $K_{\mathrm{h}}=$ 
$\sqrt{2 E_{\mathrm{k}}} l_{\mathrm{k}} S_{\mathrm{h}}$. The turbulent length $l_{\mathrm{k}}$ is related to $E_{\mathrm{k}}$ the turbulent kinetic energy (TKE) and to $\epsilon$, the dissipation rate of TKE according to

$l_{\mathrm{k}}=c_{0}^{3} E_{\mathrm{k}}^{3 / 2} \epsilon^{-1}$

$S_{\mathrm{Z}}$ and $S_{\mathrm{h}}$ the quasi-equilibrium stability functions of Kantha and Clayson (1994) depend on $E_{\mathrm{k}}, \epsilon$ and the Brunt-Vaisala frequency. The equations for $E_{\mathrm{k}}$ and $\epsilon$ (Burchard and Bolding, 2001) are

$$
\begin{aligned}
& \frac{d E_{\mathrm{k}}}{d t}=\frac{\partial}{\partial z}\left(K_{\mathrm{z}} \frac{\partial E_{\mathrm{k}}}{\partial z}\right)+P+B-\epsilon \\
& \frac{d \epsilon}{d t}=\frac{\partial}{\partial z}\left(\frac{K_{\mathrm{z}}}{\sigma_{\mathrm{k}}} \frac{\partial E_{\mathrm{k}}}{\partial z}\right)+\frac{\epsilon}{E_{\mathrm{k}}}\left(c_{1} P+c_{3} B-c_{2} \epsilon\right)
\end{aligned}
$$

where $P=K_{\mathrm{z}}\left[\left(\frac{\partial \hat{u}}{\partial z}\right)^{2}+\left(\frac{\partial \hat{v}}{\partial z}\right)^{2}\right]$ is the production term and $B=$ $\frac{g}{\rho} K_{\mathrm{h}} \frac{\partial \rho}{\partial z}$ is the buoyancy term. $\sigma_{\mathrm{k}}=1.3, c_{0}=0.5544, c_{1}=$ $1.44, c_{2}=1.92$ and $c_{3}=1$ if $B \geq 0$ and $c_{3}=-0.52$ otherwise (Warner et al., 2005).

- Bottom boundary conditions for $E_{k}$ :

The $E_{\mathrm{k}}$ bottom boundary condition is based on the assumption of the equilibrium of the production and dissipation terms $(P=\epsilon)$.

$$
E_{k_{z=-h}}=\frac{\left\|\boldsymbol{\tau}_{\text {bot }}\right\|}{\rho \sqrt{2^{0.5} c_{0}^{3} S_{\mathrm{Z}}}}
$$

\section{- Surface boundary conditions for $E_{k}$.}

Alternatively, the boundary conditions can be specified as surface flux conditions, namely: $K_{\mathrm{z}} \frac{\partial E_{\mathrm{k}}}{\partial z}=F$. Where the surface flux can be computed according to Craig and Banner (1994)

$F=100\left(\frac{\tau}{\rho}\right)^{1.5}$

with $\tau=\tau_{\mathrm{a}}-\tau_{\mathrm{aw}}+\tau_{\mathrm{wo}}$, or directly prescribed from the "wave to ocean" turbulence flux computed by a wave model when available ( $\phi_{\mathrm{oc}}$ term in WW3). The surface flux condition is believed to produce more realistic results than the $P=\epsilon$ condition (Estournel et al., 2001).

\section{- Bottom and surface boundary conditions for $\epsilon$ :}

The $\epsilon$ surface and bottom conditions are computed on the first level under the surface and above the bottom boundaries. Let $z_{1}$ denote the distance between this level and the considered boundary. Boundary conditions for $\epsilon$ are obtained from $E_{\mathrm{k}}$ and Eq. (30), using the latter with some appropriate hypothesis for $l_{\mathrm{B}}$ a boundary length scale value. A simple formulation (Warner et al., 2005) is eventually given by $l_{\mathrm{B}}=\kappa\left(z_{1}+z_{0}\right)$, where $z_{0}$ is the length scale representing the roughness of the boundary.

Unfortunately, the formulation $l_{\mathrm{B}}=\kappa\left(z_{1}+z_{0}\right)$ potentially leads to unrealistic high values, especially when the grid resolution is low. It must indeed be realized that coastal ocean models generally have to deal with strong variations of bathymetry. For $s$ coordinate models, this unavoidably results in a loss of resolution in the deepest areas of the numerical domain. A more complete formulation is thus used in our case. Following Estournel and Guedalia (1987), the stratification and the shear effects are taken into account through the use of the Richardson number $(R i)$ :

$$
\left\{\begin{array}{l}
l_{\mathrm{B}}=\kappa\left(z_{1}+z_{0}\right) \quad \text { if } \quad R i<0 \\
l_{\mathrm{B}}=\kappa\left(z_{1}+z_{0}\right)(1-5 R i) \quad \text { if } \quad 0 \leq R i \leq 0.16 \\
l_{\mathrm{B}}=\kappa\left(z_{1}+z_{0}\right)(1+41 R i)^{-0.8} \quad \text { if } \quad R i>0.16 .
\end{array}\right.
$$

Moreover, at the surface, we consider that $z_{0}=z_{\text {surf }}$ is linked to the significant wave height (Terray et al., 1996, 2000).

$z_{\text {surf }}=1.6 H_{\mathrm{s}}$

We therefore tested values between $0.8 H_{\mathrm{s}}$ and $2.4 H_{\mathrm{s}}$ which can be found in the literature (Rascle et al., 2006). Ideally, we should not use the significant wave height, but the significant wave height of the wind-sea only $H_{\text {sw }}$. Given that the swells have a small surface slope and consequently do not break, it is more appropriate to use the wave height of the wind sea only to calculate the roughness length instead of the significant wave height $H_{\mathrm{s}}$ (Rascle et al., 2008). This value is calculated according to Rascle et al. (2008) (Eq. 6), and is now available in WW3.

$E_{\mathrm{k}}$ and $\epsilon$ can not be lower than the minimum values $E_{\mathrm{k}, \min }=10^{-8} \mathrm{~m}^{2} \mathrm{~s}^{-2}$ and $\epsilon_{\min }=10^{-12} \mathrm{~m}^{2} \mathrm{~s}^{-3}$. Moreover the length scale limitation suggested by Galperin et al. (1988) is transposed to the dissipation rate of TKE, that is

$\epsilon \geq E_{\mathrm{k}} \frac{c_{0}^{3}}{0.53 \sqrt{2}} \sqrt{\frac{-g}{\rho} \frac{\partial \rho}{\partial z}}$.

\subsection{Wave model}

In order to take into account the effects of waves in the momentum equations, some quantities provided by wave models are required: period, significant wave height, direction, wavenumber, Stokes velocities, wavelength, $\boldsymbol{\tau}_{\text {aw }}$ the momentum flux from atmosphere to wave, and $\boldsymbol{\tau}_{\text {wo }}$ the momentum flux from wave to ocean linked to wave breaking. Some of them can be directly provided by the wave model, and others can be calculated from the available parameters, depending on the wave model chosen.

In the academic case studies, presented in Sect. 3, we use the SWAN wave model, and in the realistic simulation, presented in Sect. 4, we use the WW3 model, validated at global, regional and nearshore scales. These are third generation wave-averaged models that solve the two-dimensional wave action balance equations for wave action density as a function of $(\theta, \sigma)$ for the SWAN model and a function of $(\theta, k)$ for the WW3 model. In Cartesian coordinates, this equation is written as

$\frac{\partial N}{\partial t}+\frac{\partial c_{\mathrm{x}} N}{\partial x}+\frac{\partial c_{\mathrm{y}} N}{\partial y}+\frac{\partial c_{\sigma} N}{\partial \sigma}+\frac{\partial c_{\theta} N}{\partial \theta}=\frac{S_{\mathrm{tot}}}{\sigma}$ 
with $N$ the wave action density $N=\frac{E}{\sigma}, c_{\mathrm{x}}, c_{\mathrm{y}}, c_{\sigma}$ and $c_{\theta}$ the propagation velocities in $\mathrm{x}-, \mathrm{y}-, \sigma-$ and $\theta-$ space, respectively. The source/sink term, $S_{\text {tot }}$ on the right side, is expressed in terms of energy density and represents different physical processes available in the wave model:

$S_{\mathrm{tot}}=S_{\mathrm{in}}+S_{\mathrm{nl} 3}+S_{\mathrm{n} 14}+S_{\mathrm{ds}, \mathrm{w}}+S_{\mathrm{ds}, \mathrm{b}}+S_{\mathrm{ds}, \mathrm{br}}$

with $S_{\text {in }}$ the atmospheric source function, $S_{\mathrm{n} 14}$ the nonlinear quadruplet interactions and $S_{\mathrm{ds}, \mathrm{w}}$ the dissipation by whitecapping. Other phenomena induced by the finite depth effects like $S_{\mathrm{nl} 3}$ triad nonlinear wave-wave interactions, $S_{\mathrm{ds}, \mathrm{b}}$ dissipation by bottom friction and $S_{\mathrm{ds}, \text { br }}$ dissipation by depthinduced breaking are taken into account. Thus, diffraction, reflection, refraction and shoaling are included.

SWAN (version 40.72) accounts for all these processes. It is generally used for wave transformation at nearshore and coastal scales (Booij et al., 1999; Dufois, 2008; Rusu and Soares, 2009; Bruneau, 2009). We will use this model for the academic cases.

WW3 has been widely used at global and regional scales and its validity is now extended to nearshore scales (version 4.04) with parameterizations of wave breaking, bottom dissipation and wave dissipation, avoiding the use of a specific nearshore wave model. One can find more information about the parameterizations proposed by this version in Ardhuin et al. (2010). This model has been validated using in-situ and remote sensing data (Ardhuin et al., 2008a, 2010; Delpey et al., 2010).

\section{Validation of the model in two test cases}

\subsection{A normal plane beach test case}

This test case consists of obliquely incident spectral waves approaching an idealized smooth plane beach. It was initially posed by Haas and Warner (2009), hereinafter named HW09 and more recently by Uchiyama et al. (2010), hereinafter called UMS10. HW09 compared two hydrodynamic models: the quasi-3-D model SHORECIRC (Svendsen et al., 2002) and the 3-D model ROMS (Shchepetkin and McWilliams, 2005), where wave forcing followed the depth-dependent radiation stress formalism of Mellor (2003). UMS10 compared these solutions with another version of ROMS where a vortex force (McWilliams et al., 2004) approach is used. All these solutions were forced rigorously by the same wave field simulated by SWAN. We suggest comparing our model to this test case to assess its validity and performance to those of previous models.

The bathymetry is a plane beach with a constant slope of $1: 80$. It has realistic dimensions $(1180 \mathrm{~m}$ in the cross-shore direction $\mathrm{x}$ and $1200 \mathrm{~m}$ in the alongshore direction $\mathrm{y}$ ). The coast is oriented to the west and the offshore boundary is set at $x=0$ with the maximum water depth $(12 \mathrm{~m})$. We use the same grid spacing of $20 \mathrm{~m}$ in horizontal directions as in previous simulations, and 10 vertical levels. To be consistent with
UMS10 and HW09, a quadratic bottom drag law (Eq. 21) is used with a drag coefficient $C_{\mathrm{d}}$ sets constant equal to 0.0015 .

At the offshore boundary, a Jonswap type spectral modeled wave field is imposed with a $2 \mathrm{~m}$ significant wave height, $10 \mathrm{~s}$ peak period and an incidence angle of $10^{\circ}$. We use the same wave fields as HW09 and UMS10. We also neglect the roller effects and the bottom streaming. Earth rotation is excluded with the Coriolis parameter set to 0 . Lateral periodic conditions are used. As a first step, we do not take into account the influence of waves on vertical mixing and on the surface roughness length. UMS10 conducted four simulations: a 2-D barotropic case (Run a) and three 3-D cases where the vertical profiles of the vector of breaking dissipation or the vertical mixing are changed (Runs b, c and d). In Run b, the vertical penetration of momentum associated with breaking waves is concentrated near the surface, whereas in Runs c and $\mathrm{d}$, penetration is quite uniform along the vertical column. We impose for this test that our vertical profile for the momentum associated with breaking waves is similar to the Run b.

$$
\boldsymbol{F}_{\mathrm{d}}^{\text {surf }}=\frac{\boldsymbol{\tau}_{\mathrm{wo}}}{\rho} \frac{\cosh \left(\frac{z+h}{\frac{0.2}{\sqrt{2}} H_{\mathrm{s}}}\right)}{\int_{-h}^{\hat{\eta}} \cosh \left(\frac{z+h}{\frac{0.2}{\sqrt{2}} H_{\mathrm{s}}}\right) d z}
$$

UMS10 also calculated an analytical solution for the barotropic velocities and the surface elevation.

\subsubsection{Reference simulation}

Waves begin to break between $500<x<1000 \mathrm{~m}$, (as shown by the breaking dissipation rate Fig. 16a in UMS10), and the significant wave height decreases for $x=600 \mathrm{~m}$. A slight setdown before the breaking point and a set-up reaching $22 \mathrm{~cm}$ at the shoreline are observed. After two hours of simulation time, our simulation becomes stationary. Our surface elevation agrees with both the analytical and numerical results of UMS10 (Fig. 1a). The cross-shore barotropic velocity (Fig. 1b) is the same as that of UMS10 (and equal to the depth-averaged anti-Stokes flow because of the mass balance) and the alongshore barotropic velocity (Fig. 1c) almost fits the results from Run $\mathrm{b}$, with a maximum value of $0.93 \mathrm{~m} \mathrm{~s}^{-1}$ located closer offshore $(x=770 \mathrm{~m})$ than Run $\mathrm{b}$. The discrepancy between our alongshore velocity and Run $\mathrm{b}$ is explained by the use of a different turbulence closure model ( $k-\epsilon$ model instead of a KPP model in UMS10). Vertical profiles of the velocities (Fig. 2) are also consistent with the vertical profiles of Run b. Note the color palette is not saturated as in UMS10, in order to show how the crossshore velocities are sheared $\left(0.35 \mathrm{~m} \mathrm{~s}^{-1}\right.$ near the surface to $-0.4 \mathrm{~m} \mathrm{~s}^{-1}$ close to the bottom). We therefore obtain a strong and common recirculation cell in the surf zone with the current oriented onshore near the surface and offshore on the bottom. Outside of the surf zone, cross-shore velocities are almost uniform over the depth and directed offshore. They are the exact opposite of the Stokes velocities. The profile 

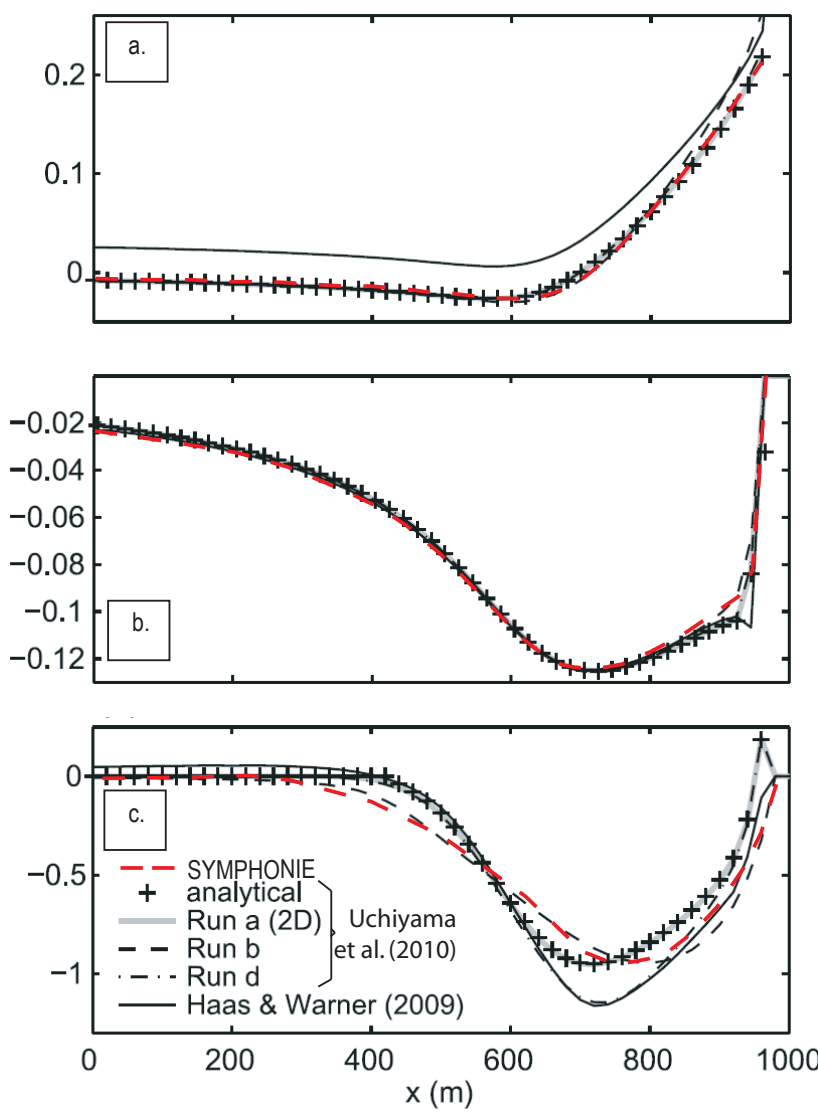

Fig. 1. Cross-shore profile of the surface elevation (a), barotropic quasi-Eulerian cross-shore (b) and longshore (c) velocities $\left(\mathrm{m} \mathrm{s}^{-1}\right)$ (adapted from UMS10). SYMPHONIE results are the red dashed line whereas ROMS results of Run $b$ are in black dashed lines. The shoreline is at right.

of $K_{\mathrm{Z}}$ is quite different close to the surface in the surf zone, from the profile of $K_{\mathrm{Z}}$ in Run b, because of our difference in the turbulence closure model as pointed out above.

We will display the depth-averaged terms of the momentum equations to describe in detail how the different forces are balanced (Fig. 3). The Stokes-Coriolis and Coriolis forces are not represented because rotation is excluded. A test with a non-null Coriolis parameter showed that these forces are negligible at this scale. We thus display the depth-averaged values of: the advection $\left(\hat{u} \frac{\partial \hat{u}}{\partial x}+\hat{v} \frac{\partial \hat{u}}{\partial y}+\hat{w} \frac{\partial \hat{u}}{\partial z}, \hat{u} \frac{\partial \hat{v}}{\partial x}+\hat{v} \frac{\partial \hat{v}}{\partial y}+\hat{w} \frac{\partial \hat{v}}{\partial z}\right)$, the vortex force $\left(\left[\frac{\partial \hat{v}}{\partial x}-\frac{\partial \hat{u}}{\partial y}\right] V_{\mathrm{s}}-W_{\mathrm{s}} \frac{\partial \hat{u}}{\partial z},\left[\frac{\partial \hat{v}}{\partial x}-\frac{\partial \hat{u}}{\partial y}\right] U_{\mathrm{s}}-W_{\mathrm{s}} \frac{\partial \hat{v}}{\partial z}\right)$ (these two last terms are the ones defined in Eqs. 2 and 3), the vertical mixing, the breaking acceleration $\left(F_{\mathrm{d}, \mathrm{x}}^{\text {surf }}, F_{\mathrm{d}, \mathrm{y}}^{\text {surf }}\right)$ (as defined in Eq. 40), the pressure gradient $\left(-\frac{1}{\rho} \frac{\partial p^{\mathrm{H}}}{\partial x},-\frac{1}{\rho} \frac{\partial p^{\mathrm{H}}}{\partial y}\right)$, the two terms of the Bernoulli's head gradient $\left(-\frac{\partial S^{\mathrm{J}}}{\partial x},-\frac{\partial S^{\mathrm{J}}}{\partial y}\right)$ and $\left(-\frac{\partial S^{\text {shear }}}{\partial x},-\frac{\partial S^{\text {shear }}}{\partial y}\right)$. As there is no surface stress, the depth-averaged vertical mixing force is reduced to the bottom stress.
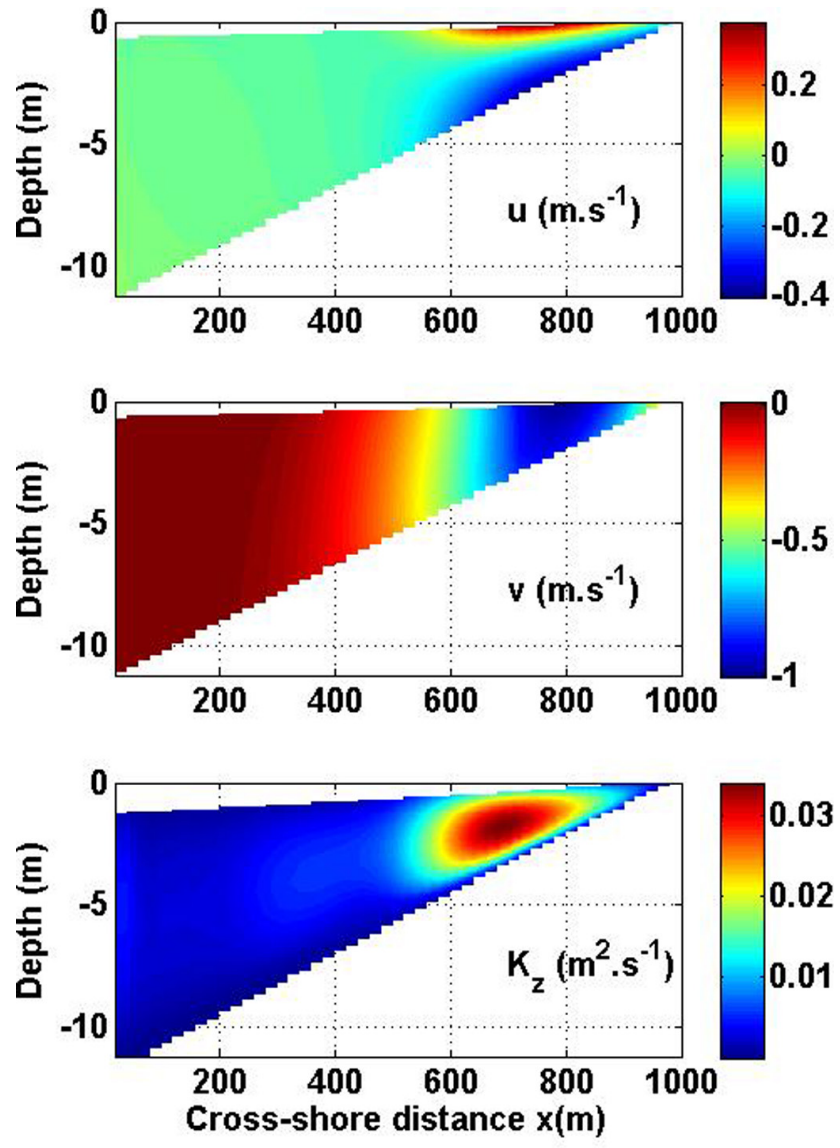

Fig. 2. Vertical sections of quasi-Eulerian cross-shore (top) and longshore (middle) velocities and of the vertical eddy viscosity $K_{\mathrm{Z}}$ (bottom) in SYMPHONIE.

The alongshore momentum balance is between four forces: the breaking acceleration drives the northward alongshore velocities, the southward bottom stress, the vortex force and the Eulerian advection. The vortex force is totally compensated by the Eulerian advection. Until $x$ reaches $690 \mathrm{~m}$, the vortex force is oriented southward and thereafter, it becomes positive and is oriented northward. The advection force has the same pattern but in an opposite sign. The depthaveraged cross-shore accelerations are one order of magnitude larger than the alongshore ones. Among the most important forces is the breaking acceleration, which is larger in the surf zone, directing the surface cross-shore velocity to the shoreline. This momentum input is competed with the pressure gradient force, which is negative in the surf zone. The depth uniform term of the Bernoulli's head gradient $-\frac{\partial S^{J}}{\partial x}$ is less important. When waves shoal before the surf zone, this force is negative and balances with the positive pressure gradient force, creating a set-down. In the surf zone, it turns positive, whereas the pressure gradient force is negative and more important. A set-up is generated. Finally, the shearinduced term of the Bernoulli's head gradient $-\frac{\partial S^{\text {shear }}}{\partial x}$ is 

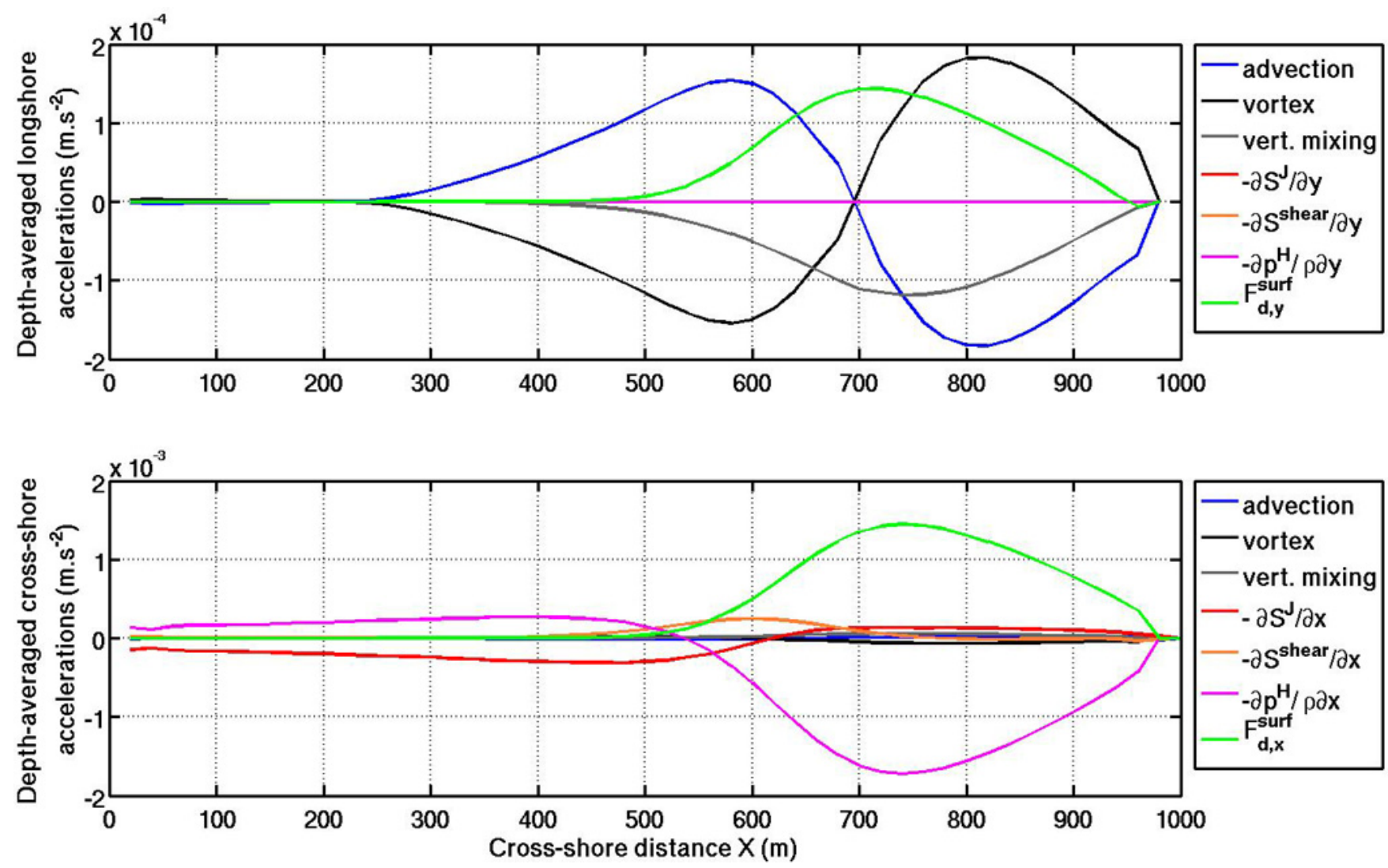

Fig. 3. Depth-averaged values of the different terms in the alongshore (top) and cross-shore (bottom) momentum balance, versus cross-shore distance: the advection, the vortex force, the vertical mixing (vert. mixing), the pressure gradient $\left(-\frac{1}{\rho} \frac{\partial p^{\mathrm{H}}}{\partial x},-\frac{1}{\rho} \frac{\partial p^{\mathrm{H}}}{\partial y}\right)$, the two terms of the Bernoulli's head gradient $\left(-\frac{\partial S^{\mathrm{J}}}{\partial x},-\frac{\partial S^{\mathrm{J}}}{\partial y}\right)$, and $\left(-\frac{\partial S^{\text {shear }}}{\partial x},-\frac{\partial S^{\text {shear }}}{\partial y}\right)$ and the breaking acceleration $\left(F_{\mathrm{d}, \mathrm{x}}^{\text {surf }}, F_{\mathrm{d}, \mathrm{y}}^{\text {surf }}\right)$.

negligible except in the offshore part of the surf zone, where it is positive. As a consequence of this term, the transition from set-down to set-up is displaced further offshore and the slope of the surface is reduced. Rascle (2007) has already noticed this in his test case.

It thus appears that the vertical profile of the velocities is widely dependent on the vertical profile of the breaking acceleration, on the vertical mixing, as well as the vertical profile of the vortex force which is related to the one of the Stokes velocities.

\subsubsection{Sensitivity tests considering the surface conditions and surface roughness}

As we have seen before, vertical shear is highly related to the vertical mixing. In this section, we test different surface boundary conditions in the parameterization of the turbulence closure. In the reference simulation, eddy viscosity was parameterized according to the $k-\epsilon$ turbulent closure scheme. At the surface, we test the addition of the condition of Craig and Banner (1994) (Eq. 34) and also different surface roughnesses $z_{\text {surf }}$ (Eq. 36). In the reference simulation, the surface roughness was fixed to $0.015 \mathrm{~m}$. We therefore test the values $0.8 H_{\mathrm{s}}$ and $2.4 H_{\mathrm{s}}$ as in Rascle et al. (2006).

The parameterization of Craig and Banner (1994) adds a flux of energy that slightly increases the vertical mixing only near the surface (Fig. 4a). The vertical profile of the crossshore velocity and the depth-integrated alongshore velocity are very close to the ones of the reference simulation (Fig. 4b and c). When the surface roughness is increased and related to the significant wave height, the vertical shear is decreased and the velocities are more depth-uniform. The alongshore velocities are thus increased and the peak is moved offshore.

In conclusion, our results agree with the previous simulations performed by other models using different theories. The littoral drift and vertical profiles are correctly reproduced by our model. Nevertheless, the sensitivity tests and the analysis show that these profiles are highly dependent on the vertical mixing and the vertical penetration of the breaking acceleration force and the Stokes velocities. Even if the model is in agreement with the others, a comparison with in-situ data or laboratory measurements is necessary to assess whether the 3-D characteristics are accurate (Sects. 3.2 and 4). 

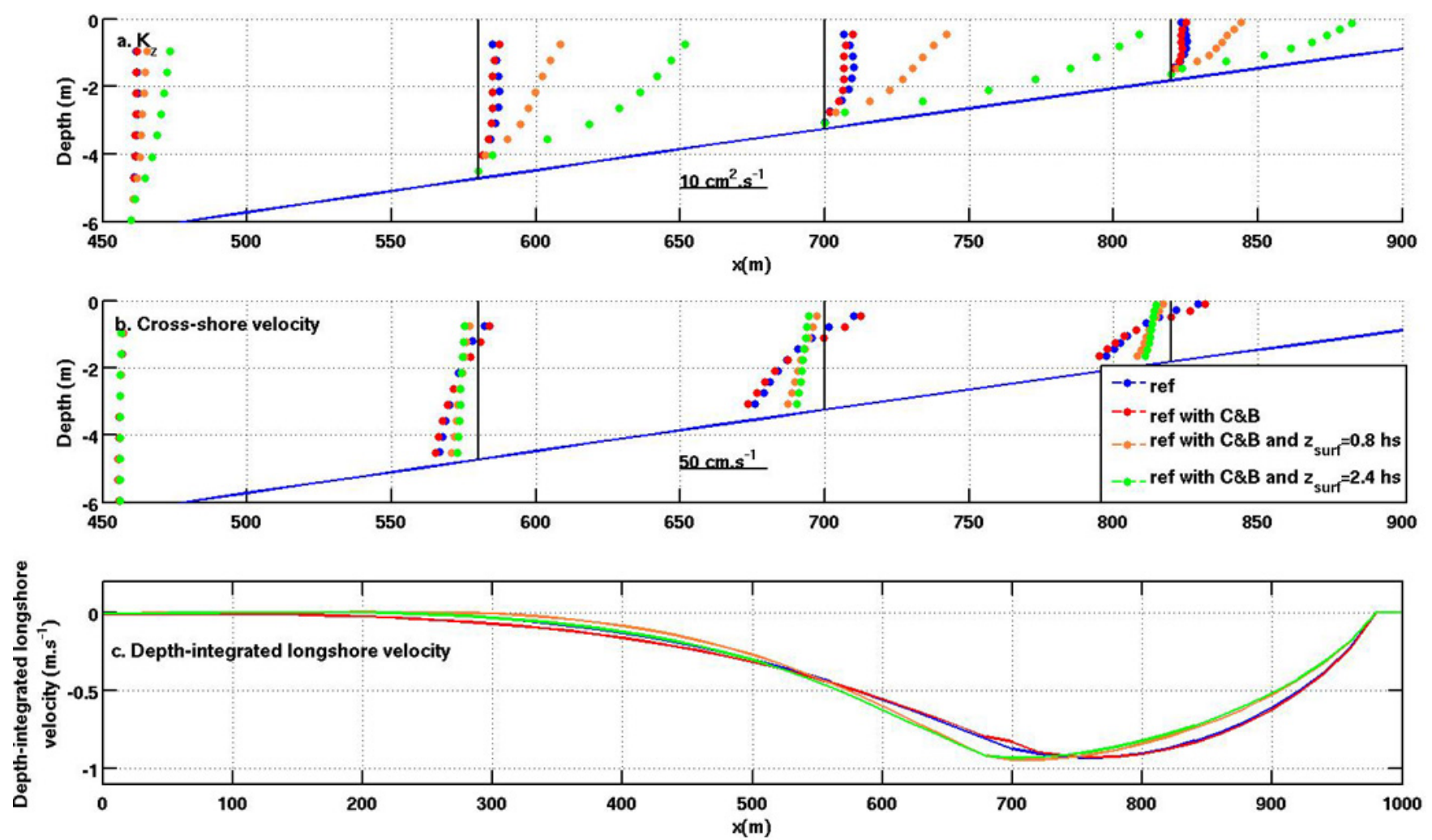

Fig. 4. Comparison of the vertical profiles of the vertical eddy viscosity (a), the cross-shore velocities (b) and the cross-shore profile of the longshore depth-integrated velocities (c) with or without the parameterization of Craig and Banner (1994)) and different surface roughnesses in the turbulence closure. "ref" is the result for the reference simulation.

\subsection{A barred beach with rip current}

The purpose of this test case is to check the ability of the model to correctly reproduce the rip current phenomena, before tackling the study of the complex sandbar systems of the Têt inner shelf. We reproduce test B experiments of Haller et al. (2002) performed in the basin of the Ocean Engineering Laboratory (University of Delaware). Previous modelers have reproduced this experiment with the SHORECIRC model (Haas et al., 2003), with MARS (Bruneau, 2009), and also with ROMS using the wave forcing radiation stress approach of Haas and Warner (2009). The size of the modeled basin is $15.8 \mathrm{~m}$ in the cross-shore direction $x$ and $18.6 \mathrm{~m}$ in the alongshore direction $\mathrm{y}$. Between $1.5 \mathrm{~m}$ and $3 \mathrm{~m}$ from the wave maker, the beach slope is steep $(1: 5)$ but it is mild $(1: 30)$ for the rest of the domain. A longshore bar system made up of three bars of $7.32 \mathrm{~m}$ in length and $6 \mathrm{~cm}$ in height, separated by rip channels of $1.82 \mathrm{~m}$, is located at $6 \mathrm{~m}$ from the coast. The grid spacing is similar to Haas et al. (2003), and is $20 \mathrm{~cm}$ in the horizontal direction. Seven vertical levels are used. We set wall conditions at the borders. Rotation is excluded. On the bottom, we use the Eq. (21) for the boundary condition.

The wave forcing is performed by SWAN. A monochromatic wave is imposed at the offshore edge with a $0.0724 \mathrm{~m}$ significant wave height and $1 \mathrm{~s}$ peak period, perpendicular to the direction of the beach (Fig. 5a). Waves break suddenly over the bar while being more progressive through the rip channel. There is a little shoaling before the breaking point above the bar, but it is insignificant through the rip channel. As previously noted by Haas et al. (2003) and Weir et al. (2011), this is because there is no forcing by the current on waves.

The cross-shore profiles of the surface elevation are different over the bar and through the channel (Fig. 5b) and consistent with Haas and Warner (2009). In fact, there is a set-up over the bar and another one near the shoreline (corresponding to the locations where waves break), whereas in the channel, the set-up is more progressive.

In previous simulations and in the experiment, two recirculation cells of current are generated by the wave forcing (Fig. 6): one in the surf zone with currents oriented shoreward over the bars and offshore above the channels, and another less marked between the bars and the shoreline. This second recirculation cell is made up of the excess of water brought by waves waiting to be evacuated offshore via the channels. Moreover, previous numerical simulations (e.g. Yu and Slinn, 2003; Haas et al., 2003; Haas and Warner, 2009) 

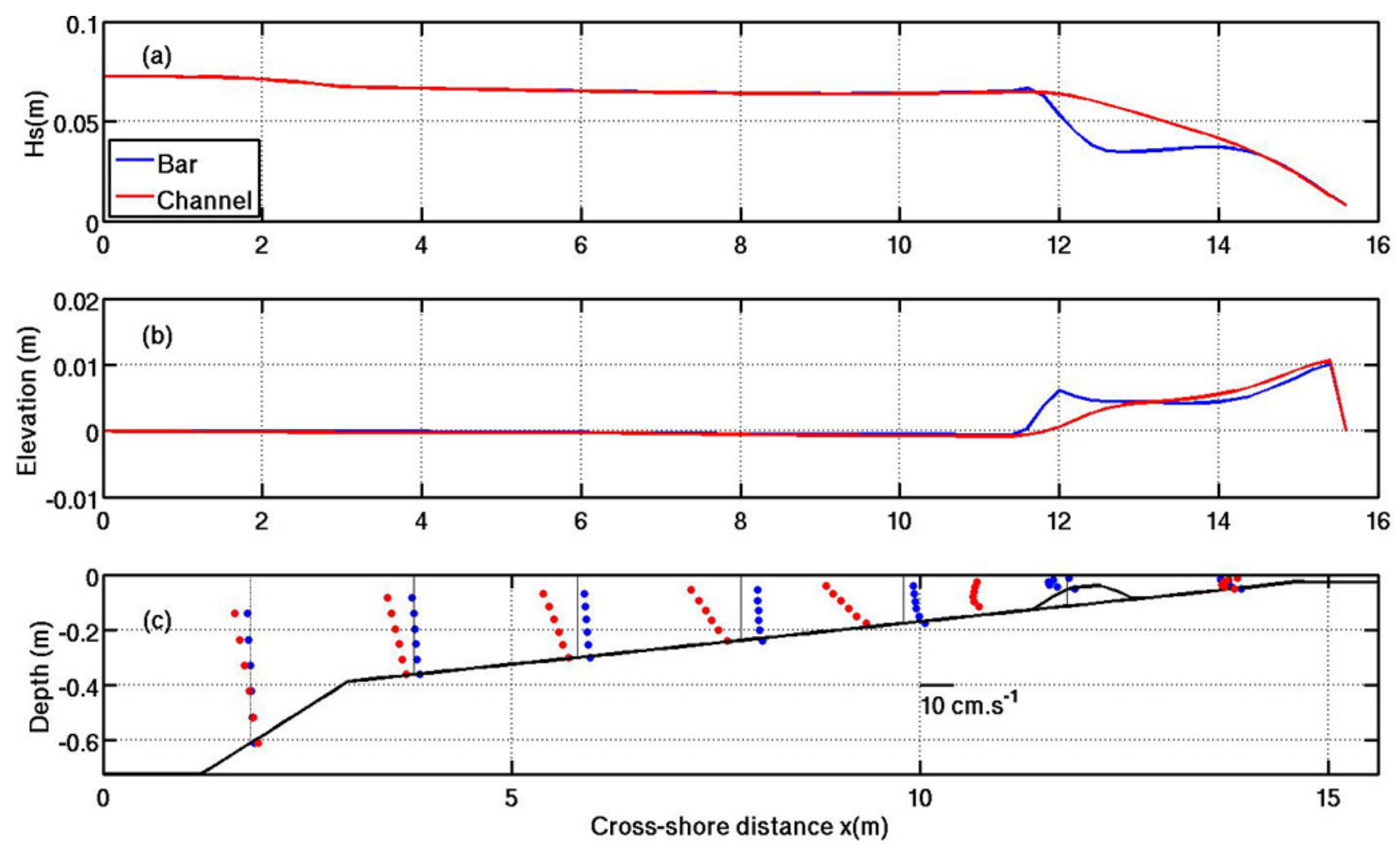

Fig. 5. Significant wave height (a), surface elevation (b) and vertical profiles of the cross-shore velocities (c) versus cross-shore distance over the center bar at $y=9.2 \mathrm{~m}$ (blue) and through the rip channel at $y=4.6 \mathrm{~m}$ (red). The shoreline is at right.

and observations (MacMahan et al., 2005) have shown that rip currents are unstable flows.

With a quadratic bottom drag law with a drag coefficient equal to 0.015 , we obtain two rip currents and also two little recirculation cells between the bars and the shoreline. However, these circulations become quickly stationary. Decreasing this coefficient to 0.00015 and the horizontal diffusion through the Smagorinsky coefficient (divided by 5), we observe that the two rip currents continually oscillate and meander to the left and right of the channel. A time-average of the circulation during $30 \mathrm{~min}$, once the oscillations are well settled, was calculated to compare with the time-averaged measurements. We observe that the rip current in the channel at the top of Fig. 6d is on average directed toward the left. This pattern is also noticed in the simulations of Haas and Warner (2009). The second time-averaged rip current is directed toward the right, but with a smaller angle. We can notice that the direction of this rip current differs from the previous simulations (Fig. 6). Different sensitivity tests have shown that this result is highly dependent on many processes, such as the bathymetry, the wave parameters, the bottom roughness, the boundary conditions, etc. Moreover, our rip currents are more extended offshore and are narrower in the channel than in the other simulations. The effects of the currents on waves not represented here, could be responsible of these differences (Smith, 2006), as Yu and Slinn (2003); Weir et al. (2011) have shown that rip currents reduce the flux of momentum from waves to currents due to wave breaking. Finally, intensities of depth-integrated currents are comparable to the data, with a maximum value equal to $0.25 \mathrm{~m} \mathrm{~s}^{-1}$.

The consistency of the current vertical profiles is hard to check because no 3-D-measurements were performed in the experiment. They are difficult to obtain in general because of the sporadic and changing nature of currents in these kinds of systems. We will thus compare our results to the ones of Haas and Warner (2009). They pointed out that above channels, cross-shore current are sheared, being stronger in the upper part of the water column. As the rip exits the channel, the velocity stays large near the surface and is weak close to the bottom, as Haas and Svendsen (2002) had observed. In our simulation (Fig. 5c), cross-shore velocities are stronger in the channel than above the bar. We obtain the same results in and downstream from the channel, with a larger current in the upper part of the water column. We also observe that above the bar, the current is stronger in the middle of the water column, and downstream, it is oriented onshore close to the bottom and is weak near the surface. In conclusion, this simulation gives reasonable results compared to the ones of Haas and Warner (2009). 

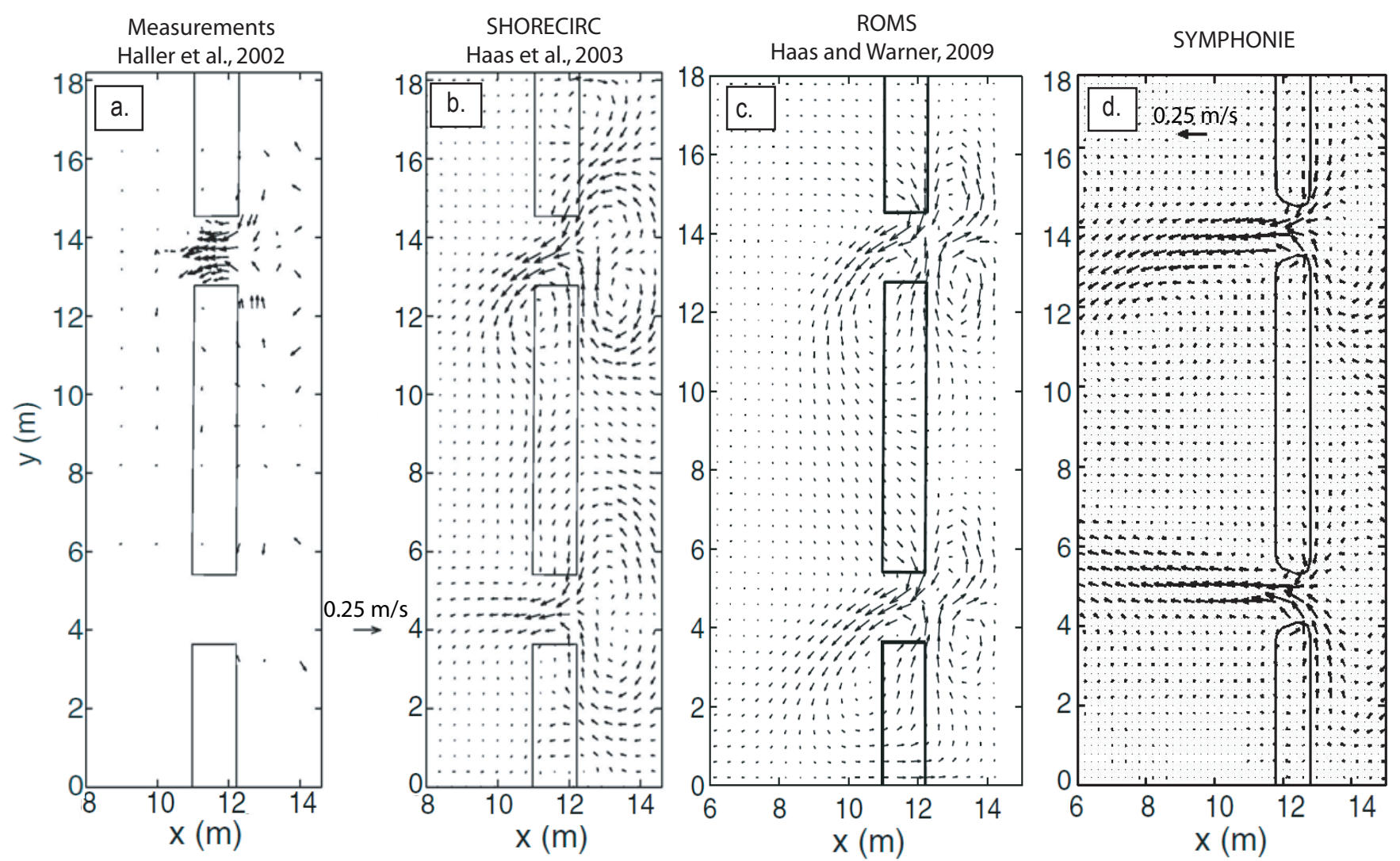

Fig. 6. Comparison of time-averaged depth-integrated current measured by Haller et al. (2002) (a), with numerical simulations done by SHORECIRC (Haas et al., 2003) (b), ROMS (Haas and Warner, 2009) (c) and SYMPHONIE (d).

These two test cases deal with littoral scales, where the wave action is the most intense. The model is able to reproduce the wave-induced processes at this scale. In the next section, a simulation at the inner-shelf scale, is performed to test the validity of our model in a region where the circulation results from a wide range of processes.

\section{Application to 21 February 2004 storm at the Têt in- ner shelf}

\subsection{General context}

\subsubsection{Coastal circulation and the Têt system}

The Têt River discharges into the southwestern part of the Gulf of Lion (hereinafter GoL) in the northwestern Mediterranean Sea (Fig. 7). Circulation in this micro-tidal zone in front of this river is strongly controlled by wind conditions. Estournel et al. (2003) and Ulses et al. (2008a) show that two major winds, the Tramontane (NW) and Marin (SE), induce cyclonic circulation in the GoL generating a southward current along the Têt coast. During east or south-east storms, this general counterclockwise circulation is intensified in the inner shelf but is opposed by an alongshore northward littoral drift. Evidence of this drift has been provided by Anguenot and Monaco (1967) with radioactive tracers, by Delpont and Motti (1994) with aerial and SPOT images, multi-date remote sensing by Certain (2002) and by Bourrin et al. (2008), who analyzed bathymetric and sediment data.

The Têt is a small river with an average water discharge of less than $10 \mathrm{~m}^{3} \mathrm{~s}^{-1}$, with exceptional peaks two orders of magnitude higher during high precipitation events (Serrat et al., 2001). The littoral zone, where it discharges, has a complex bathymetry. A recent LiDAR (Light Detection and Ranging) survey (Fig. 8) shows a sand spit developing northwards of the breakwaters of the Canet-en-Roussillon harbor, followed by a deep pit, as observed by Bourrin et al. (2008). Thereafter, complex double crescentic sandbar systems, classified as low tide terraces (LTT) by Aleman et al. (2011), are observed. They appear chaotic and are likely disturbed by the breakwaters of the harbour and the river. The internal bars have their left side more onshore than their right side, suggesting that they have been modified by the northward littoral drift. 


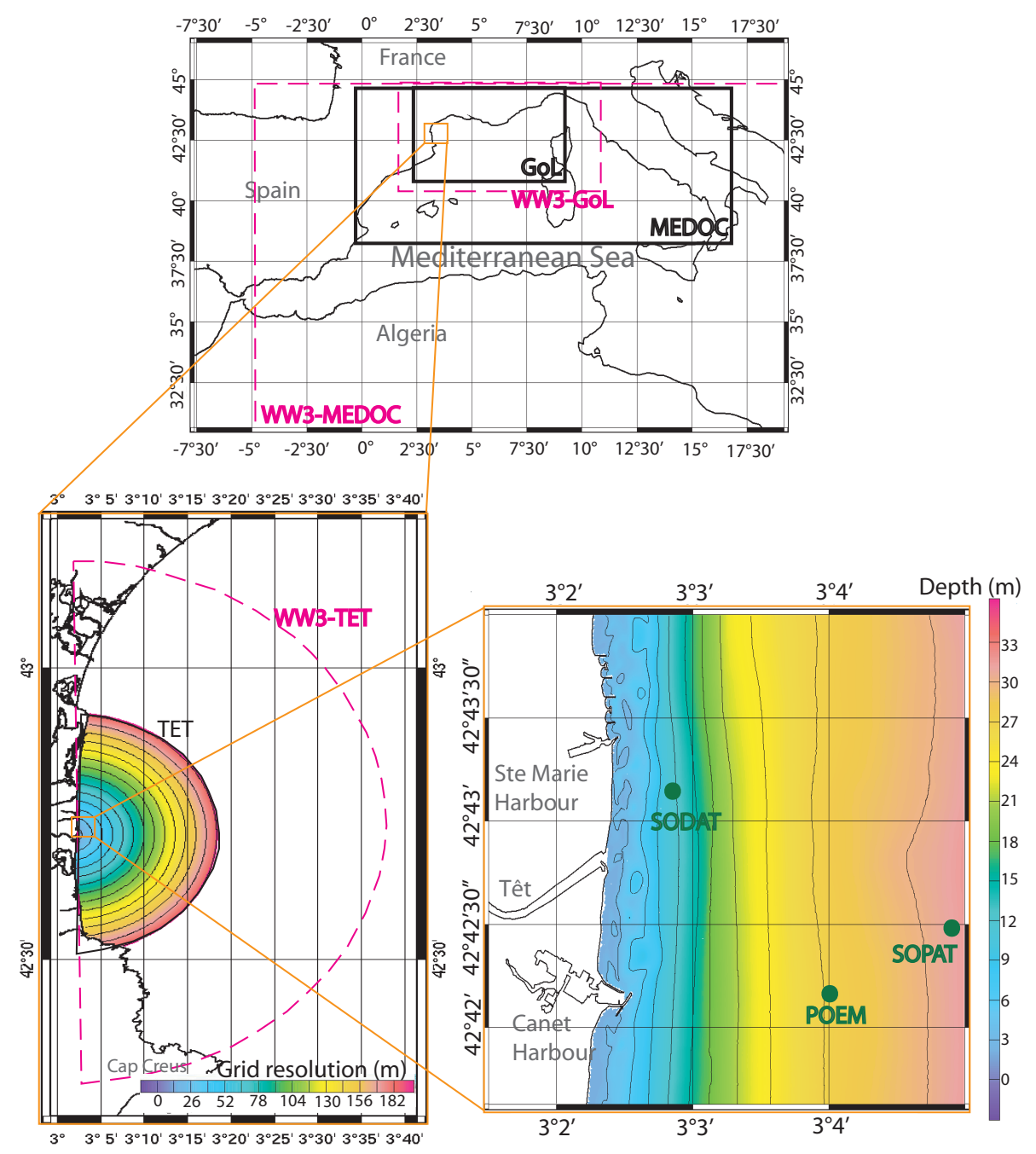

Fig. 7. The three embedded domains used by SYMPHONIE (black frame) and WW3 (dashed pink frame) for the Têt inner shelf simulation and positions of the three instruments.

\subsubsection{Instrumental devices}

As part of the Eurostrataform program (Weaver et al., 2006), a field observation program was conducted from November 2003 to April 2004 in order to characterize the sediment transfer from the river to the slope, then to the open ocean. Meteorological, sedimentological and hydrodynamic data were collected. The wind field was measured every $1 \mathrm{~h}$ at the Meteo-France Toreilles meteorological station located $8 \mathrm{~km}$ further north of the Têt mouth. A $600 \mathrm{kHz}$ Teledyne RDI Sentinel ADCP, equipped with a wave gauge, was deployed on the inner shelf at a depth of $28 \mathrm{~m}$ and $2 \mathrm{~km}$ from the river mouth (POEM point, position: $42^{\circ} 42.25^{\prime} \mathrm{N}$, $03^{\circ} 04.01^{\prime} \mathrm{E}$, Fig. 7). It collected wave and current data between 26 November 2003 and 16 January 2004 and between 4 February 2004 and 26 March 2004. The sampling rate was set to $20 \mathrm{mn}$ every $3 \mathrm{~h}$ at $2 \mathrm{~Hz}$ for wave measurements, and currents were measured at $1.5 \mathrm{~Hz}$ between the wave mea- surement bursts. The ADCP was set in a trawl bottom mount and turned toward the surface to record currents with 23 cells of $1 \mathrm{~m}$ of resolution. Between 11 February 2004 and 21 June 2004, an Acoustic Doppler Profiler (ADP) Nortek AWAC was positioned at a depth of $11 \mathrm{~m}$ (SODAT point, position: $42^{\circ} 43.23^{\prime} \mathrm{N}, 03^{\circ} 02.89^{\prime} \mathrm{E}$ ) (Fig. 7) in front of the Têt river, in order to measure the current as well as waves (using a wave pressure sensor) every $30 \mathrm{~min}$. The ADP was set on the sea bottom and looked upward, with 9 cells of $1 \mathrm{~m}$. Lastly, between 11 February 2004 and 14 January 2005, a $600 \mathrm{kHz}$ Aquadopp Profiler, located at a depth of $31 \mathrm{~m}$ (SOPAT point, position: $42^{\circ} 42.59^{\prime} \mathrm{N}, 03^{\circ} 04.78^{\prime} \mathrm{E}$ ) (Fig. 7) measured current profiles every $5 \mathrm{~min}$ with cells of $2 \mathrm{~m}$. It was fixed to a buoy, looking downward. 


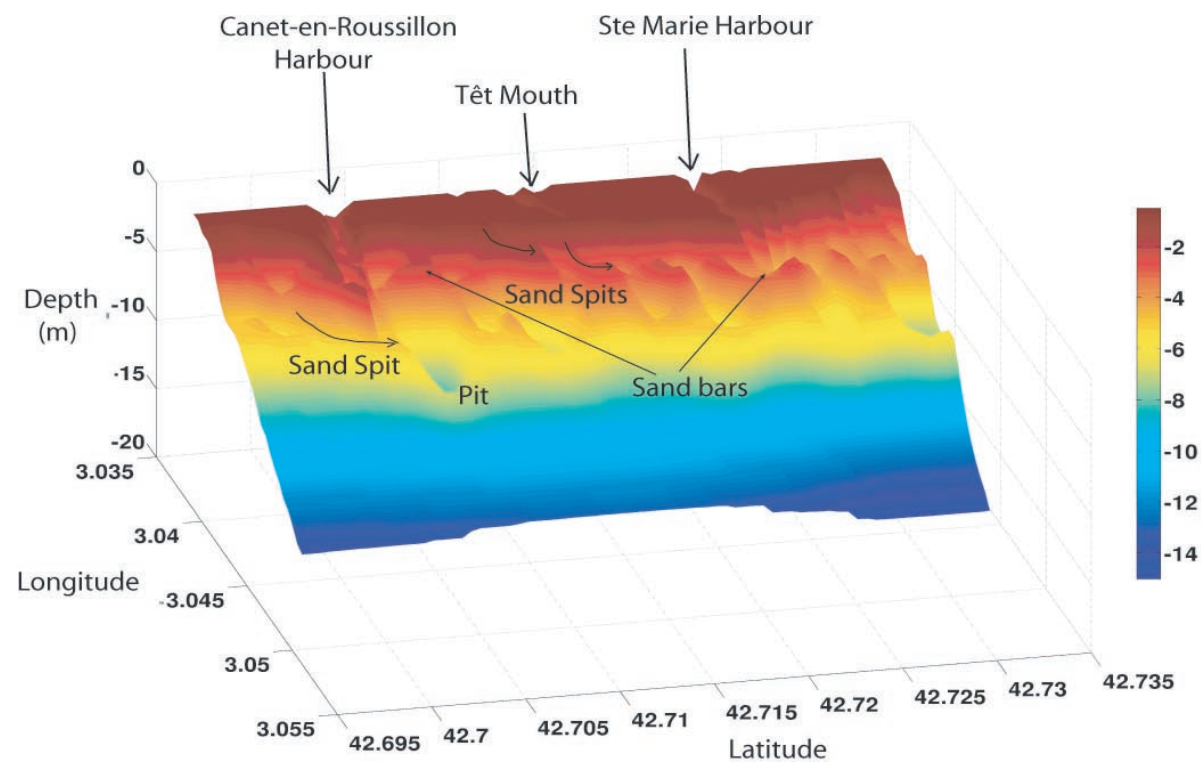

Fig. 8. The Têt bathymetry measured by the LiDAR survey. The distance between each measurements is $5 \mathrm{~m}$. The developments of northward sand spits in front of the river mouth or the Canet-en-Rousillon harbour are clearly visible.

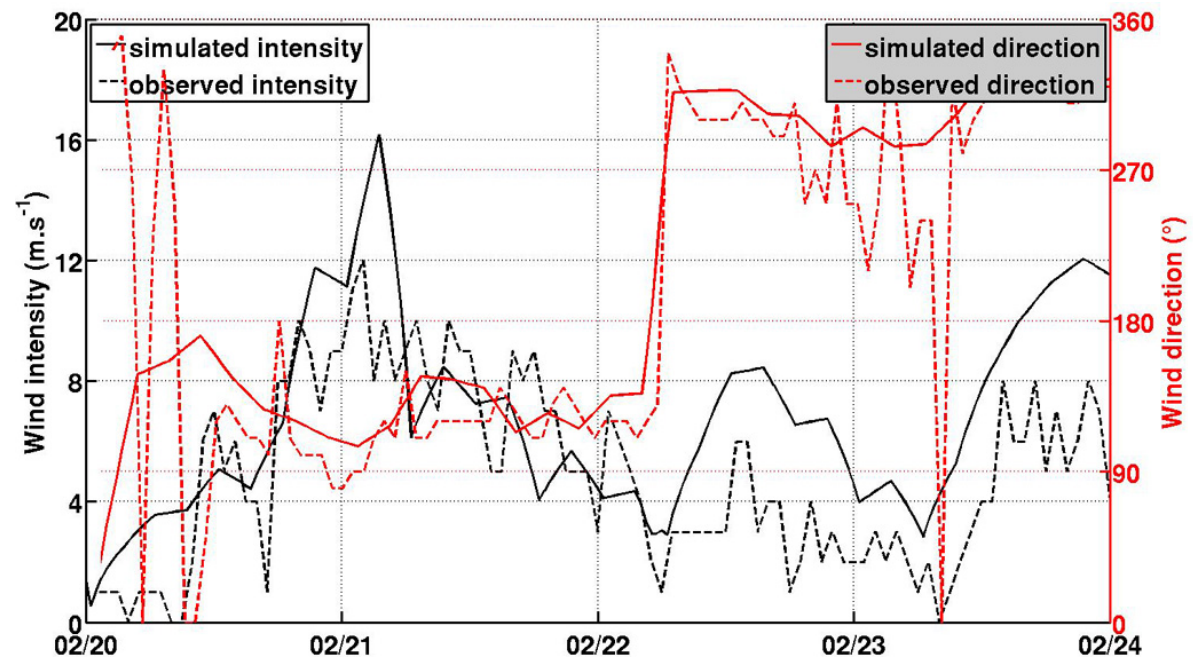

Fig. 9. Simulated (solid line) and observed (dashed line) wind intensity (black) and direction (red). The data are provided by the Toreilles station and simulated wind is given at the SODAT station.

\subsubsection{The storm of 21 February 2004}

During the sampling period, two major storms occurred, one on 4 December 2003 and another on 21 February 2004 (Guillén et al., 2006). We focus on the second storm since more data are available for this period. The storm was characterized at SOPAT by a maximum significant wave height $H_{\mathrm{S}}>7 \mathrm{~m}$ and a peak period $T>12 \mathrm{~s}$, with a westward peak direction (Guillén et al., 2006). At SODAT, significant wave height reached $6 \mathrm{~m}$ at 5 a.m. (Figs. 10 and 11) while the wind blew out of the south-east and reached up to $16 \mathrm{~m} \mathrm{~s}^{-1}$ (Fig. 9). The water and sediment discharge of the Têt, as es- timated by Guillén et al. (2006), were very low compared to the previous storm (only $450 \mathrm{t}$ of sediment compared to $20000 t$ in December). Wind and waves were thus the predominant forcing during this storm. According to Guizien (2009), the return period for both storms was 10.5 years at Sète (located $100 \mathrm{~km}$ to the north-east) and 5 years at Banyuls (located $20 \mathrm{~km}$ further south). Before and after the storm, the current was southward at SODAT (11 m) (Figs. 12, 13), with low intensity $\left(<10 \mathrm{~cm} \mathrm{~s}^{-1}\right)$. At the beginning of the day (21 February), the direction of the current at SODAT turned toward the north, and the current increased in intensity to reach approximately $90 \mathrm{~cm} \mathrm{~s}^{-1}$ throughout the water column 

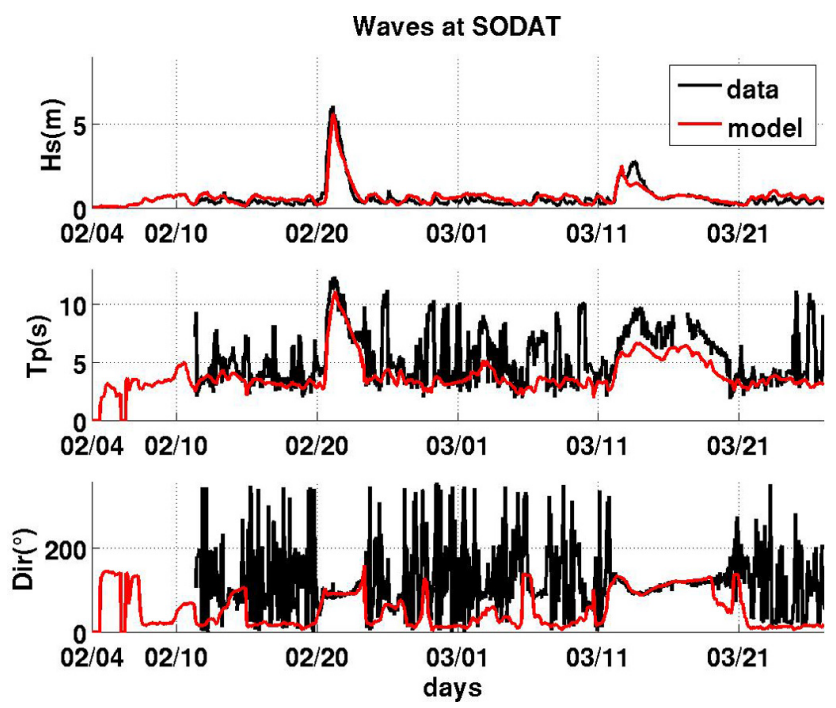

Fig. 10. Comparison of wave parameters between data and simulation at SODAT $(11 \mathrm{~m})$.

at 4 a.m. of the same day. Its intensity remained high, but then began to decrease after $4 \mathrm{~h}$, remaining at moderate intensity (around $20 \mathrm{~cm} \mathrm{~s}^{-1}$ ) for $30 \mathrm{~h}$ while the direction turned southward. At POEM (28 m) and SOPAT (31 m) (Figs. 12, 13), the current was generally oriented southward. During the storm, when wind strengthened, it increased reaching about $50 \mathrm{~cm} \mathrm{~s}^{-1}$ at the surface, and $40 \mathrm{~cm} \mathrm{~s}^{-1}$ near the bottom. At these two offshore stations, the current remained abnormally strong $\left(>15 \mathrm{~cm} \mathrm{~s}^{-1}\right)$ for more than $50 \mathrm{~h}$.

\subsection{Implementation and results}

We aim to accurately reproduce phenomena induced by waves and current, covering scales from the whole western Mediterranean Sea to the Têt nearshore zone. A first attempt consisted of using four nested grids for the hydrodynamic circulation model (with grid resolutions between $2.5 \mathrm{~km}$ and $15 \mathrm{~m}$ ). Using this set up, spurious flows were observed near the shoreline at the northern boundary of the finest grid. This was due to the representation of the littoral drift that strongly depends on the resolution of the model. As pointed out by Davies and Jones (1996), one solution is to use an unstructured grid or a grid with a variable resolution, that covers the entire Têt inner-shelf, with a fine resolution at the Têt mouth which is gradually reduced to a coarser resolution in offshore zones. Using such grids ensures a smooth transition between offshore and nearshore zones. We choose this second approach here.

\subsubsection{Wave model implementation and results}

We use three nested grids to model the sea state, two structured grids that cover the whole western Mediterranean Sea and the Gulf of Lion, respectively, and an unstructured grid,

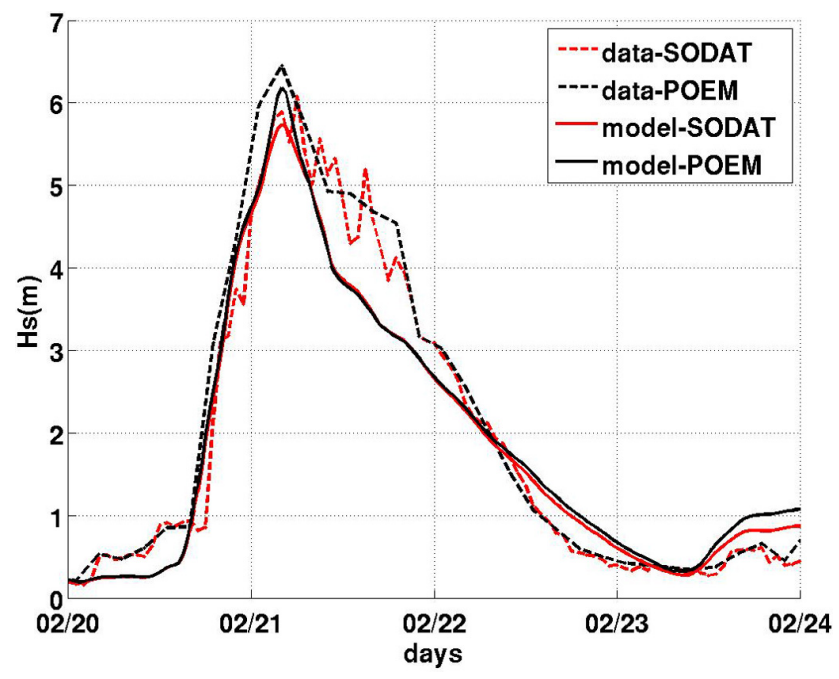

Fig. 11. Comparison of significant wave height at SODAT (11 m) and POEM $(28 \mathrm{~m})$ in the model and the measurements.

which runs from the inner-shelf with a resolution of $550 \mathrm{~m}$ at the offshore boundaries to the surf zone of the Têt (Fig. 7 and Table 1). The size of the cells is $22 \mathrm{~m}$ near the Têt mouth. The grid is made of 64000 nodes and 127500 elements.

Simulations are run with WW3 for a period of two months, from 4 February 2004 to 26 March 2004 (the period for which observations are available). We use the TEST405 parameterizations as described in Ardhuin et al. (2010), which are more adapted for the younger seas that occur in the Mediterranean Sea. The wind velocities are provided by the Aladin model (a regional weather forecasting model focused on France with a resolution of $10 \mathrm{~km}$ ) from Météo-France every $3 \mathrm{~h}$, except for WW3-MEDOC where Aladin is supplemented by Arpege (a global atmospheric model from MétéoFrance with a grid resolution of $15 \mathrm{~km}$ over France). Output wave spectra are discretized over 36 directions with $10^{\circ}$ of resolution and 30 frequencies $f_{n}$ spaced with the relation $f_{n+1}=1.1 f_{n}$ from $0.05 \mathrm{~Hz}$ to $0.8 \mathrm{~Hz}$. Bathymetry in the Têt surf zone is complex and the length of sand bars ranges between $200-300 \mathrm{~m}$. To correctly reproduce the wave breaking, and consequently the wave-induced current, it is necessary to simulate the waves with a resolution coherent with the size of the bars. A resolution of $22 \mathrm{~m}$ is used near the Têt in this study.

We compare the wave model results to the significant wave heights and wave periods recorded by the two wave gauges (SODAT and POEM) during the winter campaign (Figs. 10 and 11) and by analyzing the statistical values of correlation coefficient (COR), bias (BIAS), root mean square error (RMSE) and scatter index (SI). If $N$ is the number of observed and simulated values, $S_{i}$ the simulated values, $O_{i}$ the observed values, $S$ and $O$ the mean of simulated and 
Table 1. Computational grids used in this study: $N \lambda$ and $N \theta$ are the numbers of points in longitude $\lambda$ and latitude $\theta$, and $\delta t$ is the maximum global time step.

\begin{tabular}{lllllll}
\hline Grids & Resolution & Latitude & Longitude & $N \lambda$ & $N \theta$ & $\delta t(\mathrm{~s})$ \\
\hline WW3-MEDOC & $0.1^{\circ}$ & $31^{\circ} \mathrm{N}$ to $45^{\circ} \mathrm{N}$ & $-5.6^{\circ} \mathrm{E}$ to $16.3^{\circ} \mathrm{E}$ & 141 & 220 & 400 \\
WW3-GoL & $0.02^{\circ}$ & $41.28^{\circ} \mathrm{N}$ to $44.45^{\circ} \mathrm{N}$ & $2.02^{\circ} \mathrm{E}$ to $11.86^{\circ} \mathrm{E}$ & 117 & Longitude & $\begin{array}{l}\text { Number } \\
\text { of nodes }\end{array}$ \\
\hline Grids & $\begin{array}{l}\text { Maximum } \\
\text { resolution }\end{array}$ & $\begin{array}{l}\text { Minimum } \\
\text { resolution }\end{array}$ & Latitude & & 300 \\
\hline WW3-TET & $22 \mathrm{~m}$ & $550 \mathrm{~m}$ & $42.272^{\circ} \mathrm{N}$ to $43.158^{\circ} \mathrm{N}$ & $3.018^{\circ} \mathrm{E}$ to $3.621^{\circ} \mathrm{E}$ & 64000 & 5 \\
\hline
\end{tabular}

Table 2. Statistical comparison between data and simulations at WW3-TET scale, at SODAT and POEM.

\begin{tabular}{llllll}
\hline Position & Parameters & COR & BIAS & RMSE & SI \\
\hline \multirow{2}{*}{ SODAT $(11 \mathrm{~m})$} & Period & 0.5833 & $-0.2574 \mathrm{~s}$ & 2.3137 & 0.4133 \\
& Wave height & 0.9580 & $0.1841 \mathrm{~m}$ & 0.2869 & 0.2727 \\
POEM $(28 \mathrm{~m})$ & Period & 0.7203 & $-0.1279 \mathrm{~s}$ & 1.4206 & 0.3103 \\
& Wave height & 0.9330 & $0.2311 \mathrm{~m}$ & 0.3507 & 0.3345 \\
\hline
\end{tabular}

observed values, respectively, then the statistical values are

$$
\left\{\begin{array}{l}
\mathrm{COR}=\frac{\sum_{i=1}^{N}\left(S_{i}-\bar{S}\right)\left(O_{i}-\bar{O}\right)}{\sqrt{\sum_{i=1}^{N}\left(S_{i}-\bar{S}\right)^{2} \sum_{i=1}^{N}\left(O_{i}-\bar{O}\right)^{2}}} \\
\mathrm{BIAS}=\sqrt{S-\bar{O}} \\
\mathrm{SI}=\sqrt{\frac{\sum_{i=1}^{N}\left(S_{i}-O_{i}\right)^{2}}{\sum_{i=1}^{N}\left(S_{i}\right)^{2}}} \\
\mathrm{RMSE}=\sqrt{\frac{\sum_{i=1}^{N}\left(S_{i}-O_{i}\right)^{2}}{N}}
\end{array}\right.
$$

Statistical results show a good agreement between the two datasets and the simulation (Table 2). For example, a correlation of $93 \%$ is found for the significant wave height at POEM and $96 \%$ at SODAT. During the storm period (Figs. 10 and 11), the three parameters fit well. We note, however, that significant wave heights are underestimated by the model (Fig. 11), with a bias of $20 \mathrm{~cm}$ at the storm apex and especially during the afternoon, with a bias of $1.5 \mathrm{~m}$. We suspect this discrepancy to be linked to a wrong estimation of the wind. A comparison between wind intensity measured at the Toreilles meteorological station and the one simulated at SODAT (Fig. 9) shows that the Aladin model seems to be in reasonable agreement with the data. However, this result is not convincing as the wind over the sea is expected to be stronger than the wind on land. A sensitivity test with another atmospheric model has been performed, showing that depending on the models, wave heights can be under or overestimated. Satellite wind data have been examined to find evidences of this underestimation but the absence of valid data near the coast did not allow to draw a conclusion.

Finally, observations and simulations both indicate that significant wave height decays between the two sites, suggesting that wave dissipation occurs in the inner shelf zone.

\subsubsection{Current model implementation}

As for the wave model, three nested grids for the circulation model are deployed, with the focus towards the Têt nearshore (Fig. 7). All details concerning the different grids are presented in Table 3. Grid TET is a stretched curvilinear horizontal grid with a variable horizontal resolution (Madec, 2008), from $8 \mathrm{~m} \times 8 \mathrm{~m}$ at the nearest grid point from the Têt mouth to $180 \mathrm{~m} \times 180 \mathrm{~m}$ at the external border. Bathymetries from Berné et al. (2002) and from the LiDAR for the nearshore are used. The last one has a resolution of $5 \mathrm{~m}$ that is consistent with a grid resolution of $8 \mathrm{~m}$. As explained above, a high resolution near the river mouth is necessary in order to reproduce all current patterns generated by the crescentic sandbars that impacted the SODAT instrument. Daily river discharges were provided by Banque Hydro and Compagnie Nationale du Rhone (http://www.hydro.eaufrance.fr/). The meteorological forcings (surface pressure, air temperature, relative humidity, wind velocity and radiative fluxes) are taken from the Aladin model every $3 \mathrm{~h}$. The regional circulation model (grid MEDOC) is initialized and forced every day by the large-scale Ocean General Circulation Model (OGCM, Tonani et al., 2008). The wave forcing is not been taken into account in the circulation model at the regional scale (MEDOC) but at all other scales, every $3 \mathrm{~h}$ for the GoL, and every $1 \mathrm{~h}$ for TET. The roughness length is set to $1 \mathrm{~cm}$ throughout the domain. 
Table 3. Computational grids used in the circulation model. $i_{\max }$ and $j_{\max }$ are respectively the numbers of points in the west-east and south-north directions.

\begin{tabular}{lllllll}
\hline Grids & Resolution & Longitude & Latitude & $i_{\max }$ & $j_{\max }$ & levels \\
\hline MEDOC & $2500 \mathrm{~m}$ & $-0.39^{\circ} \mathrm{E}$ to $11.65^{\circ} \mathrm{E}$ & $38.39^{\circ} \mathrm{N}$ to $44.44^{\circ} \mathrm{N}$ & 402 & 270 & 40 \\
GoL & $800 \mathrm{~m}$ & $3.03^{\circ} \mathrm{E}$ to $5.75^{\circ} \mathrm{E}$ & $41.98^{\circ} \mathrm{N}$ to $43.57^{\circ} \mathrm{N}$ & 278 & 222 & 36 \\
TET & from $8 \mathrm{~m}$ to $180 \mathrm{~m}$ & $3.027^{\circ} \mathrm{E}$ to $3.313^{\circ} \mathrm{E}$ & $42.506^{\circ} \mathrm{N}$ to $42.925^{\circ} \mathrm{N}$ & 378 & 394 & 15 \\
\hline
\end{tabular}
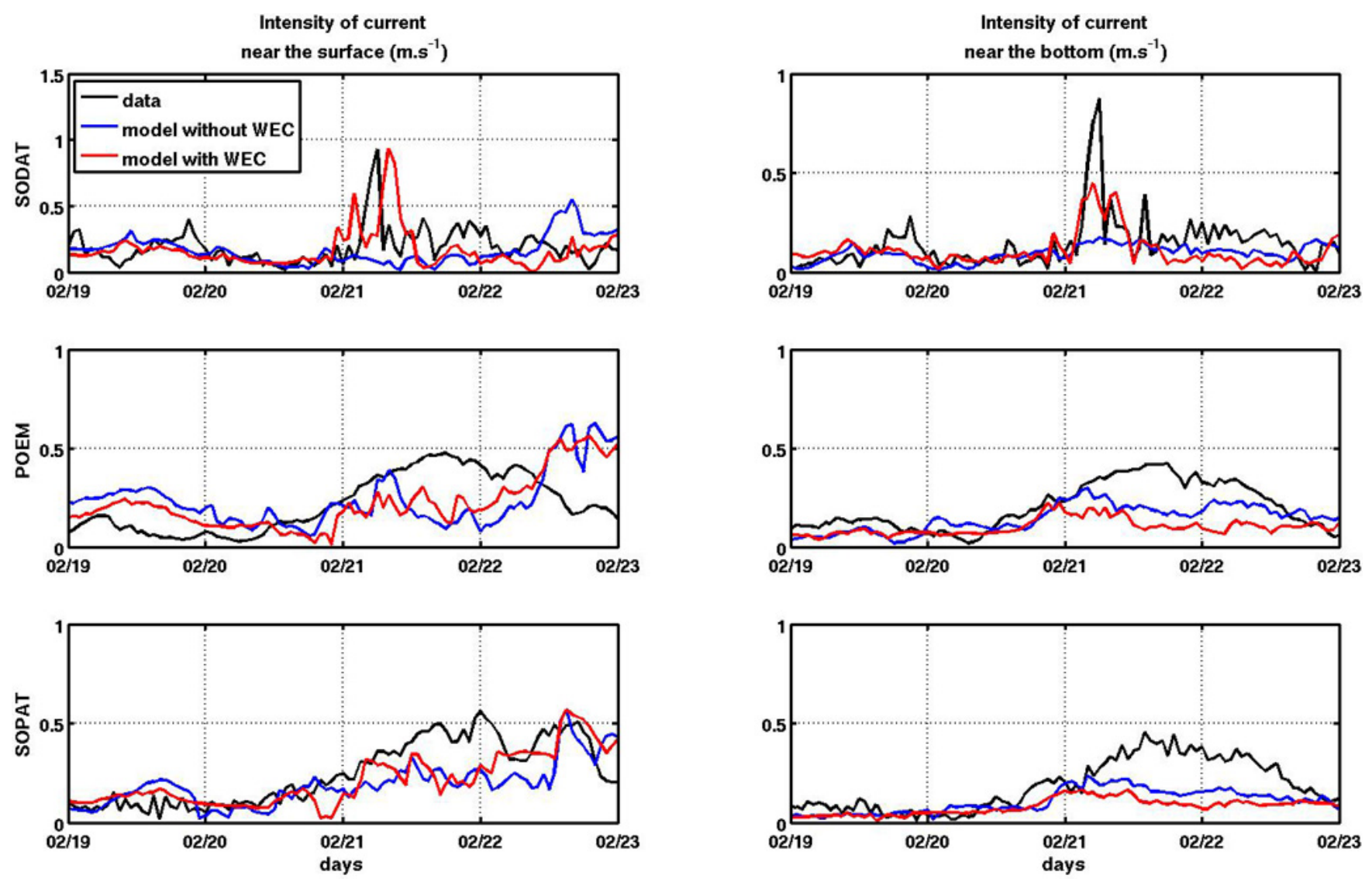

Fig. 12. Comparison of the current intensity near the bottom (right) and close to the surface (left) at the three instruments, between the measured current (black) and the simulated current with (with WEC - red) and without the wave forcing (without WEC - blue).

\subsubsection{Hydrodynamic results and discussion}

\section{Importance of the wave forcing}

Firstly, a simulation without wave forcing (Figs. 12, 13) is performed. All other forcing terms are present, including the wind and the larger scale circulation. Simulated currents are very small, and neither littoral drift nor rip currents are observed. At SODAT $(11 \mathrm{~m})$, current intensity is $0.17 \mathrm{~m} \mathrm{~s}^{-1}$ close to the surface and near the bottom. It is directed southward throughout the water column. This value is not consistent with the measured values. At POEM (28 m) and SOPAT $(31 \mathrm{~m})$, current intensities increase similarly to the measure- ments in the first hours of the storm but decrease too soon after the apex.

\section{Current in the surf zone}

At the beginning of the storm, waves propagate from the east, with the irregularities of the bathymetry creating alongshore variations in breaking wave heights (Fig. 14), which in turn are responsible for the complex recirculation cells (Fig. 15, top) and oscillating meanders in the surf zone (Bowen, 1969). These types of meanders are often observed (e.g. Reniers et al., 2001) at Palm Beach in Australia. In fact, when waves have a near normal angle of incidence, we have seen in Sect. 3.2 for the second test case that over a bathymetry 

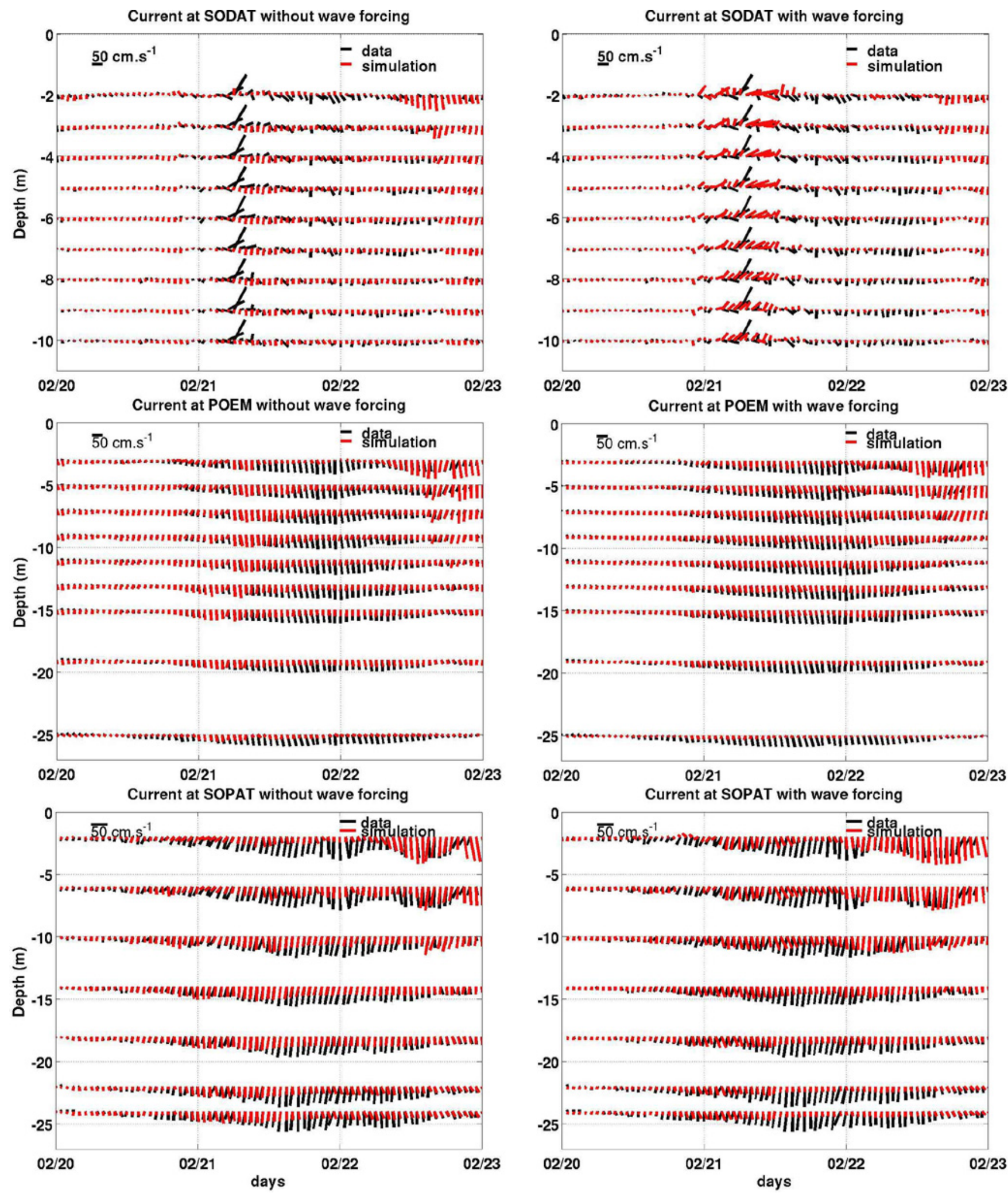

Fig. 13. Comparison of time series at the three instruments, between the measured current (black) and the simulated current (red). Left: the simulation is performed without the wave forcing, and right: the simulation is performed with the wave forcing. 


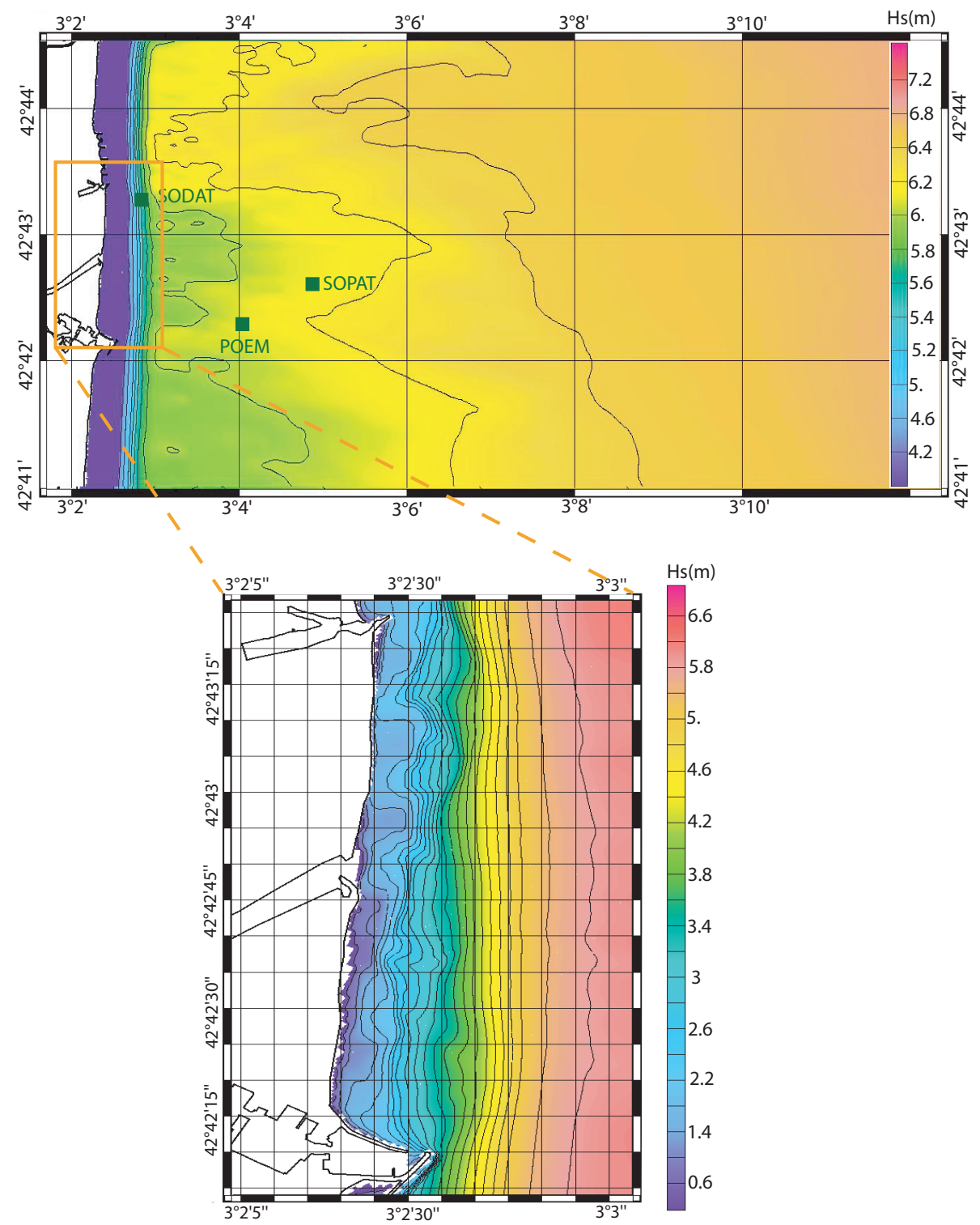

Fig. 14. Significant wave height at the storm apex on 21 February 2004 at 04:19 a.m.

made of bars and channels, the current is dominated by a rip-current flow and not a longshore drift. This is what we observe here (sections 1 and 2 in Fig. 15). A bar, at a depth of $2.5 \mathrm{~m}$ in section 1 , is able to break waves and generates a strong feeder current that circulates through to the beach and exits offshore near section 2, where the breaking bar is too close to the shore and waves are already broken. The rip current dynamics are more complex than in the test case, and largely influenced by the Canet harbour tip. Vertical sections show that over the breaking bar (Fig. 16a), crossshore velocities are stronger close to the surface $\left(>0.8 \mathrm{~m} \mathrm{~s}^{-1}\right)$ and directed onshore almost everywhere. Above the channel (Fig. 16b), current is oriented seaward everywhere, and is stronger in the middle of the water column.
On 21 February around 2 a.m., the incident direction turns and breaking waves arrive at the coast obliquely from the east-south-east. They create a longshore northward drift almost everywhere between $5 \mathrm{~m}$ and $12 \mathrm{~m}$ of water depth (Fig. 15, bottom). Some recirculation cells are still observed in the surf zone and pertubate the path of the northward drift. Locally, the Canet harbour in the south of the domain disturbs the longshore drift by shifting it offshore. These results are consistent with the development of sand spits growing northwards at river mouths, sand bars and harbours, as observed by Delpont and Motti (1994); Bourrin et al. (2008) and in the LiDAR bathymetry. Downstream from the harbour, since the beginning of the storm, a cyclonic eddy and a return current along the northern breakwater of the harbour are generated, as discussed by Trampenau et al. (2004). 

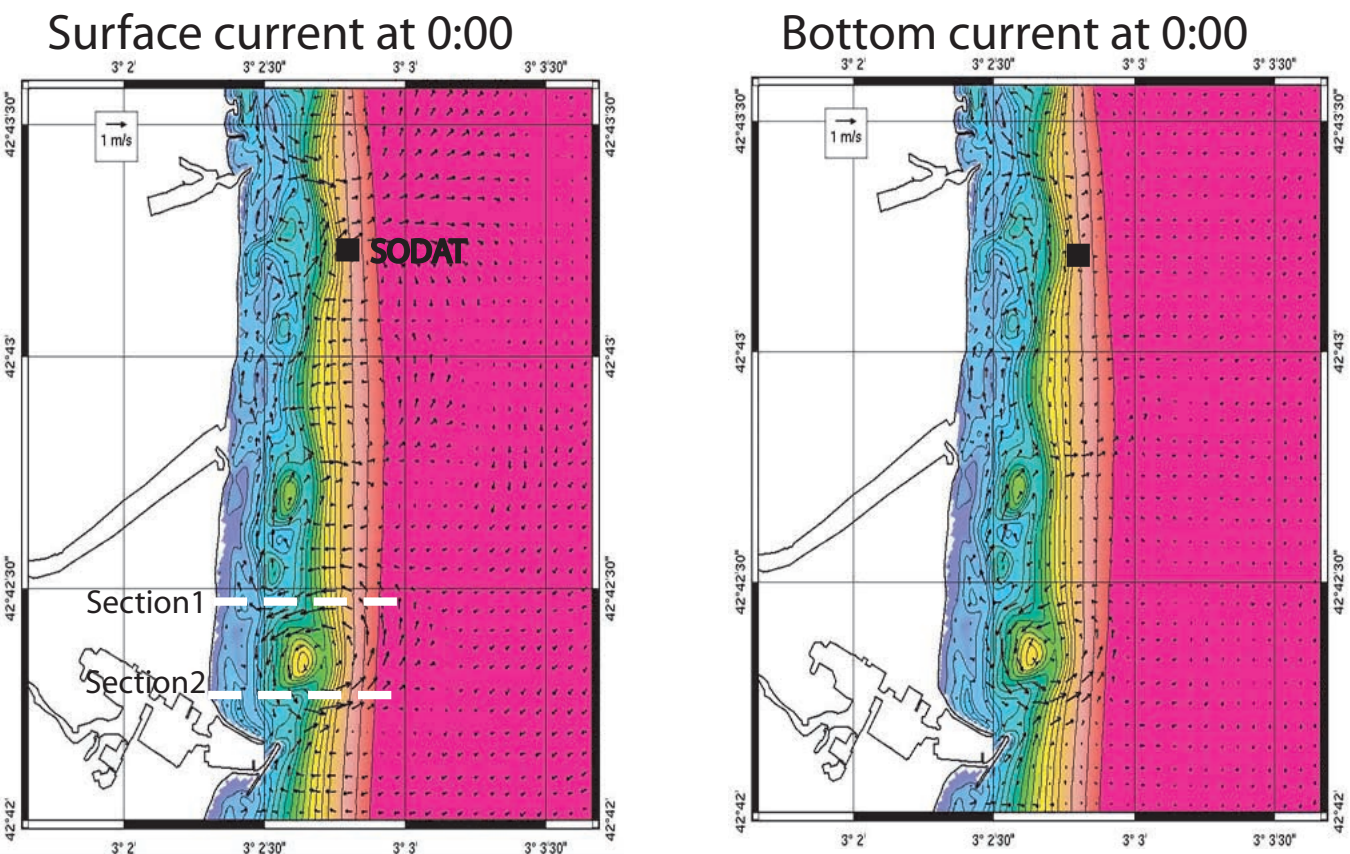

\section{Bathymetry}

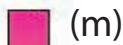

Surface current at 4:30 a.m.

Bottom current at 4:30 a.m.
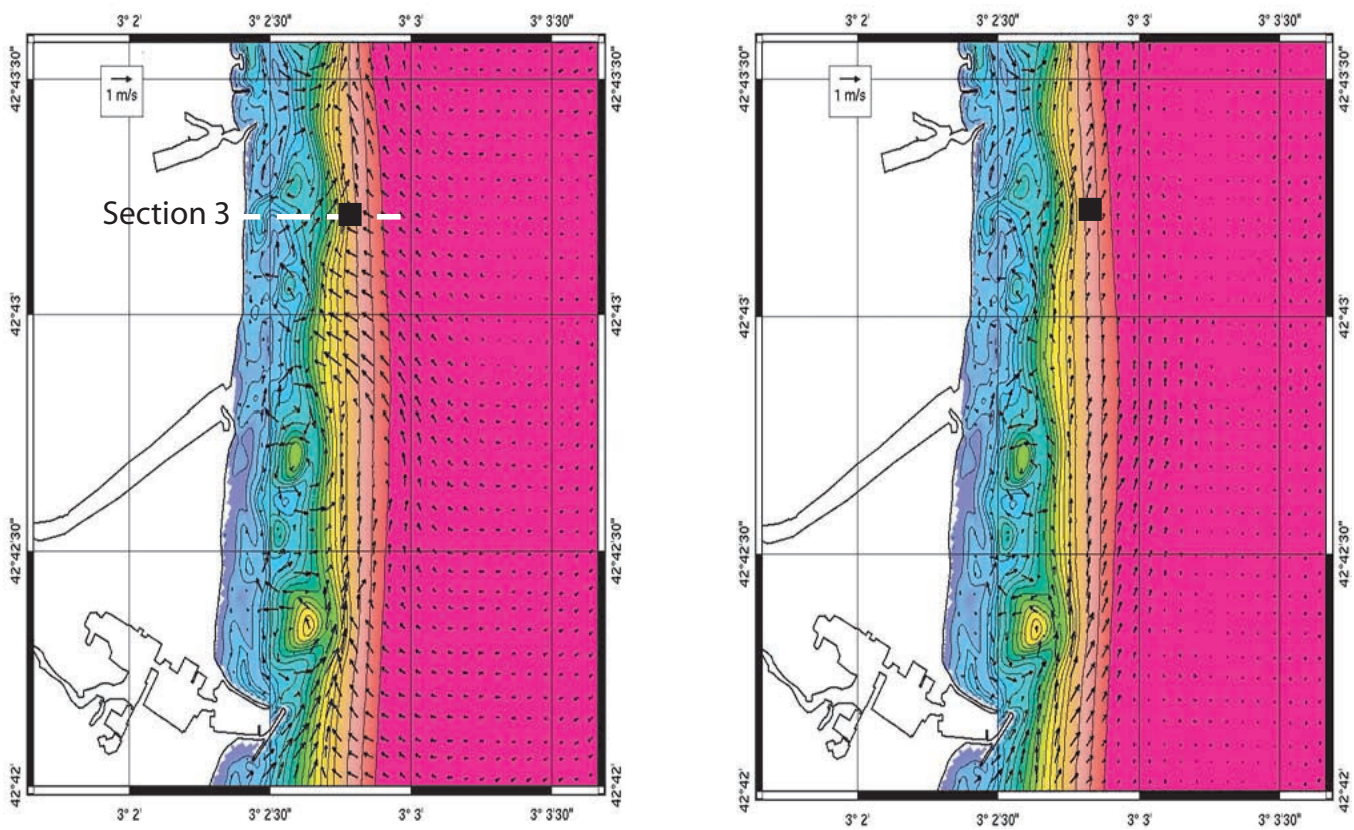

Fig. 15. Two different current patterns at an interval of $4.5 \mathrm{~h}$ :

- Surface and bottom current on 21 February at 0:00 a.m. during the rising stage of the storm

- Surface and bottom current on 21 February at 4:30 a.m. at the storm apex

The color palette indicates the bathymetry, whereas the arrows are the current vector. Position of the SODAT instrument is indicated with the black spot, as well as the position of the cross-shore sections of the following figure. Surface current is at $1 \mathrm{~m}$ of water depth under the sea surface and bottom current is at $1 \mathrm{~m}$ above the bottom. Circulations in the surf zone are mainly driven by the Bernoulli head, wave breaking dissipation forces and also pressure gradient. Theses forces have similar orders of magnitude. 

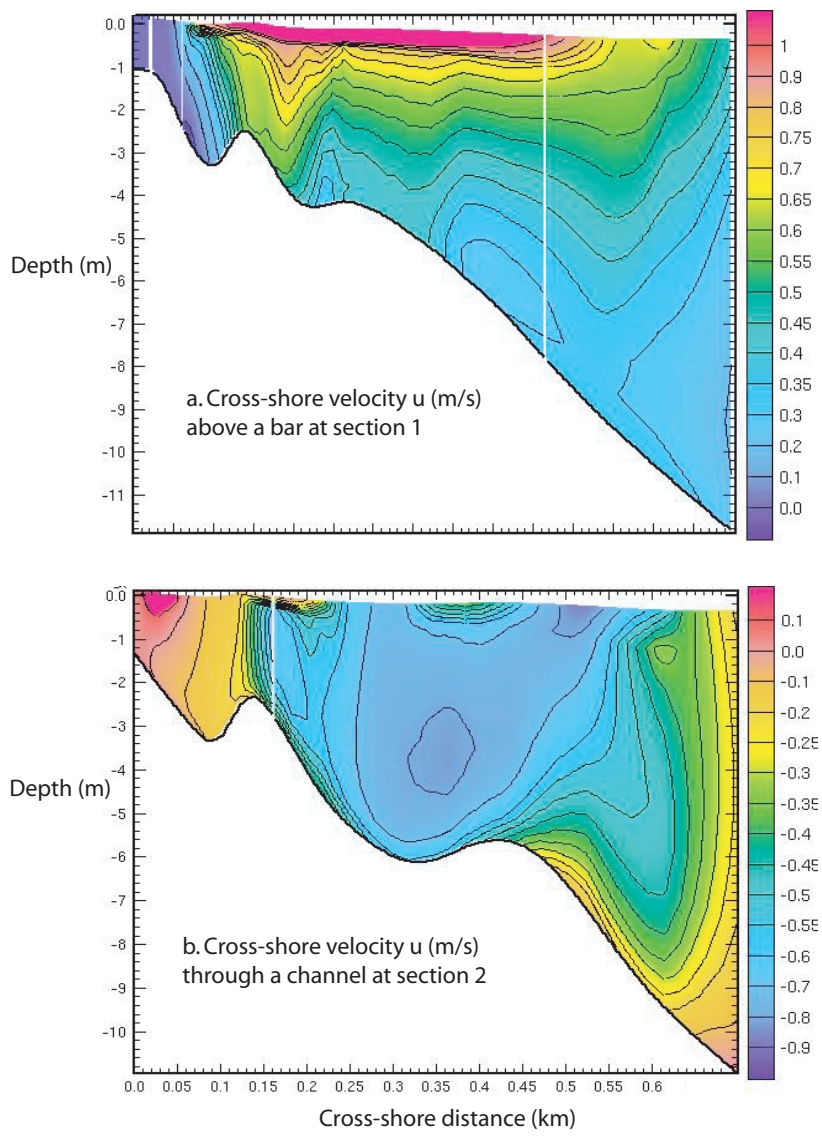

Fig. 16. Vertical sections of the cross-shore velocity (positive toward the shore) above a bar (a, section 1) and through a channel (b, section 2) during the rising stage of the storm. Positions of the sections are indicated in Fig. 15.

These phenomena explain the strong erosion observed here and in general along the harbour side in the lee of the waves (Trampenau et al., 2004). The direction of the drift is not as simple as in the first test case, and vertical profiles of current are difficult to analyse because recirculation, rip currents and littoral drift are present and interact. In the drift, however, current is quite uniform with depth (Fig. 13, top and Fig. 17).

We compare the simulated currents with the measured currents at SODAT (Figs. 12, 13). Regarding the rotation of the measured current during the rising stage of the storm (Fig. 13), it seems that the instrument is first in a zone perturbated by a rip current and then in the longshore drift. This is confirmed by the simulation. In fact, in the first hours of the storm (between 11 p.m. on 20 February and 4 a.m. on 21 February), the intensity of the rip current reaches $55 \mathrm{~cm} \mathrm{~s}^{-1}$ close to the surface (at $1 \mathrm{a} . \mathrm{m}$. on 21 February) (Figs. 13 and 15) and with a direction globally toward the east. The measurement shows an eastward current with weaker intensities $\left(<20 \mathrm{~cm} \mathrm{~s}^{-1}\right)$. The accuracy of the rip current simulation is highly dependent on the bathymetry. The modelled bathymetry, built from the LiDAR survey con-

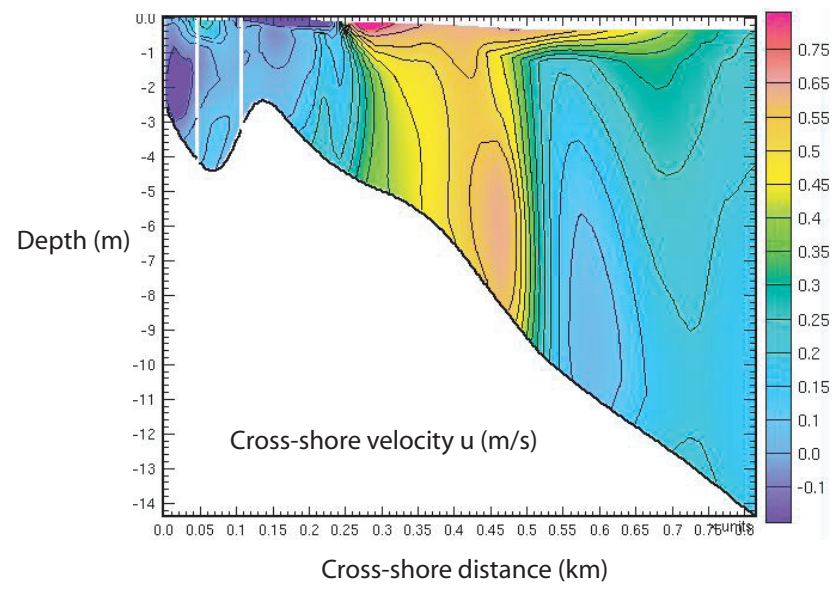

Fig. 17. Vertical section (corresponding to section 3 in Fig. 15) of the cross-shore velocity at the storm apex.

ducted in 2008, four years after this studied storm, could be the cause of the discrepancy between simulated and observed current. At 6 a.m. i.e. the storm peak, the simulated current turns towards the east-north-east. Intensity of the current is well reproduced (it reaches $90 \mathrm{~cm} \mathrm{~s}^{-1}$ at the surface and $45 \mathrm{~cm} \mathrm{~s}^{-1}$ at the bottom) with a delay of $2 \mathrm{~h}$, while the simulated direction is rather eastward than northward at least near the surface. Locally, a recirculation cell strongly influences the circulation, but outside this local pattern, the northward drift dominates the circulation (Fig. 15). In addition, near the bottom, the simulated current is underestimated $\left(45 \mathrm{~cm} \mathrm{~s}^{-1}\right.$ against $85 \mathrm{~cm} \mathrm{~s}^{-1}$ in the reality) (Fig. 12). The misrepresentation of the bottom roughness could contribute to increase the error on the roughness of the model, which largely influences the bottom current. A sensitivity test was performed and proved that the drift intensity in the entire water column was increased when the roughness was decreased.

\section{Current on the inner shelf}

On the whole inner shelf (depth $>25 \mathrm{~m}$ ), simulated currents are southward during the entire period and are intensified during the storm.

At POEM (28 m) and SOPAT (31 m), the simulated currents with and without the wave forcing have quite the same intensities (middle of Figs. 12, 13). Theses results show that waves have little effect on current at this scale. In the first hours of the storm, simulated current fits the data, but underestimates them thereafter.

The discrepancy between model results and observation may be explained by an underestimation of the wind speed, as it has been suggested in Sect. 4.2.1. A test where we increase the wind speed by a factor of 1.2 in the circulation model shows that in the surf zone results are unchanged, but on the inner shelf, current intensities reach the observed values at the surface, and are increased in the entire water 
column. This sensitivity test reveals that circulation on the inner shelf is highly dependent on the atmospheric forcing and the regional circulation, whereas in the surf zone, processes linked to waves are the most important. Moreover, it also shows that either the atmospheric model underestimates wind speed over the sea during storms, or the calculation of the surface wind stress is not adapted when the sea roughness is increased by waves. This discrepancy in current between model and observation during a storm at coastal scales is the focus of the study of Michaud et al. (2012).

\section{Conclusions}

We have developed and implemented a new method to take into account the impact of waves on the 3-D circulation. This method can be used from the nearshore to the global scale. It is first tested on two classical academic cases. Results fit with previous simulations performed by other models and with available observational data.

A realistic case was then simulated of energetic waves arriving at a coast of the northwest Mediterranean for which currents were available at different depths as well as an accurate bathymetric database of the $0-10 \mathrm{~m}$ depth range. A grid nesting approach was used to account for the different forcings acting at different spatial scales. The simulation coupling the effects of waves and currents is successful to reproduce the powerful northward littoral drift in the $0-15 \mathrm{~m}$ depth zone, while without waves, the current is slow in the opposite direction. More precisely, two distinct cases were identified: when waves have a normal angle of incidence with the coast, they are responsible for complex circulation cells and rip currents in the surf zone, and when they travel obliquely, they generate a northward littoral drift. These features are more complicated than in the test cases, due to the complex bathymetry and the consideration of wind and non-stationary processes. Wave impacts in the inner shelf are less visible since wind and regional circulation seem to be the predominant forcings. In addition, the discrepancy between model and observations is noted at that scale, possibly linked to the underestimation of the wind stress. A perspective of this study could be to fully couple wave and circulation models. This means to also take into account the effects of current on waves in the wave model. This future work will allow to estimate the potential effect of current on wave properties through blocking or refraction itself impacting the circulation through modification of the water level.

Lastly, during storm events, a classical sediment transport approach without wave forcing (e.g. Ulses et al., 2008b) does not permit the reproduction of either the northward transport in the surf zone or the transport of large amount of fine particles discharged most of the time during events combining high waves and floods. Moreover, the bottom shear stress would be strongly underestimated and then, also the possibility of resuspension for coarse sediment. In the specific case of the region studied here, we expect to extend the study of Ulses et al. (2008b) on the impact of storms on the sediment transport at regional scale to the nearshore zones. We will be then able to study the fate of sediments ranging from the river and the beach to the open ocean and so complete the study undertaken by Palanques et al. (2011).

\section{Appendix A}

Equations of Bennis et al. (2011) are in the $x$ direction (we only consider the vortex force, advection and temporal propagation):

$$
\begin{aligned}
& \frac{\partial \hat{u}}{\partial t}+\hat{u} \frac{\partial \hat{u}}{\partial x}+\hat{v} \frac{\partial \hat{u}}{\partial y}+\hat{w} \frac{\partial \hat{u}}{\partial z}= \\
& {\left[\left(\frac{\partial \hat{v}}{\partial x}-\frac{\partial \hat{u}}{\partial y}\right)\right] V_{\mathrm{s}}-W_{\mathrm{s}} \frac{\partial \hat{u}}{\partial z}+\ldots}
\end{aligned}
$$

By adding on each side the term $\frac{\partial \hat{u}}{\partial x} U_{\mathrm{s}}+\frac{\partial \hat{u}}{\partial y} V_{\mathrm{s}}+\frac{\partial \hat{u}}{\partial z} W_{\mathrm{s}}$, we find

$$
\frac{\partial \hat{u}}{\partial t}+u \frac{\partial \hat{u}}{\partial x}+v \frac{\partial \hat{u}}{\partial y}+w \frac{\partial \hat{u}}{\partial z}=\frac{\partial \hat{u}}{\partial x} U_{\mathrm{s}}+\frac{\partial \hat{v}}{\partial x} V_{\mathrm{s}}+\ldots
$$

On the left member, we add $\hat{u}\left(\frac{\partial u}{\partial x}+\frac{\partial v}{\partial y}+\frac{\partial w}{\partial z}\right)$ which is equal to zero (Eq. 5). We thus obtain

$$
\begin{array}{r}
\frac{\partial \hat{u}}{\partial t}+\frac{\partial u \hat{u}}{\partial x}+\frac{\partial v \hat{u}}{\partial y}+\frac{\partial w \hat{u}}{\partial z}= \\
\frac{\partial \hat{u}}{\partial x} U_{\mathrm{s}}+\frac{\partial \hat{v}}{\partial x} V_{\mathrm{s}}+\ldots
\end{array}
$$

We come back to the Eqs. (6) and (7).

Acknowledgements. We thank Y. Uchiyama and J. C. Warner for sharing the SWAN model data and for discussions. We thank the DREAL of Languedoc Roussillon for the LiDAR bathymetry, Xavier Durrieu de Madron (CEFREM, Perpignan), Safege-Cetiis for the in-situ data and the post-treatment. We warmly thank Cyril Nguyen and the POC crew for their assistance and Fiona Tummon for her proofreading. We acknowledge Meteo-France for the ALADIN and ARPEGE for the model outputs. We thank also MOON (the Mediterranean operational oceanography network) for OGCM outputs. This study was supported by the GMMC (groupe mission mercator coriolis). H.M. is financially supported by the CNRS and the Languedoc-Roussillon Region. F.A. is supported by a FP7-ERC young investigator grant number 240009 for the IOWAGA project. This work is also a contribution to the EPIGRAM project, funded by CNRS (national programm LEFE/IDAO) and ANR (grant ANR-08-BLAN-033001 ). The Symphonie ocean model is developed by the SIROCCO group. Sources are available at http://sirocco.omp.obs-mip.fr/ outils/Symphonie/Sources/SymphonieSource.htm. We thank the two anonymous reviewers for their comments and suggestions on the manuscript.

Edited by: J. M. Huthnance 


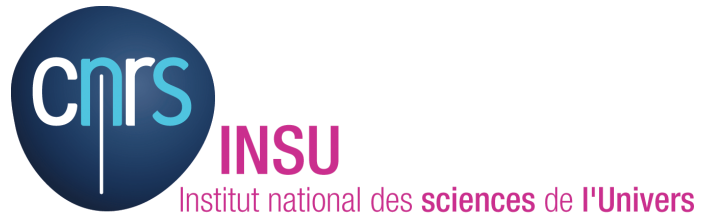

The publication of this article is financed by CNRS-INSU.

\section{References}

Agrawal, Y. C., Terray, E. A., Donelan, M. A., Hwang, M. A., Williams III, A. J., Drennan, W. M., Kahma, K. K., and Kitaigorodskii, K. K.: Enhanced dissipation of kinetic energy beneath surface waves, Nature, 359, 219-233, 1992.

Aleman, N., Robin, N., Certain, R., Vanroye, C., Barusseau, J., and Bouchette, F.: Typology of nearshore bars in the Gulf of Lions (FRANCE) using LIDAR technology, J. Coastal Res., 64, 721$725,2011$.

Andrews, D. and McIntyre, M.: An exact theory of non-linear waves on a Lagrangian mean flow, J. Fluid Mech., 89, 609-646, 1978.

Anguenot, F. and Monaco, A.: Etude des transits sédimentaires sur le littoral du Roussillon par la méthode des traceurs radioactifs, Cahiers Océanographiques, 19, 579-589, 1967.

Ardhuin, F., Chapron, B., and Elfouhaily, T.: Waves and the Air-Sea Momentum Budget: Implications for Ocean Circulation Modeling, J. Phys. Oceanogr., 34, 1741-1755, 2004.

Ardhuin, F., Collard, F., Chapron, B., Queffeulou, P., Filipot, J.-F., and Hamon, M.: Spectral wave dissipation based on observations: a global validation, in: Proceedings of the chinese-german joint symposium on hydraulic and ocean engineering, edited by Zanke, U and Roland, A and Saenger, N and Wiesemann, JU and Dahlem, G, pp. 391-400, Chinese-German Joint Symposium on Hydraulic and Ocean Engineering, Darmstadt, Germany, 2430 August 2008, 2008a.

Ardhuin, F., Jenkins, A. D., and Belibassakis, K. A.: Comments on "The Three-Dimensional Current and Surface Wave Equations", J. Physical Oceanogr., 38, 1340-1350, doi:10.1175/2007JPO3670.1, 2008b.

Ardhuin, F., Rascle, N., and Belibassakis, K.: Explicit wave-averaged primitive equations using a generalized Lagrangian mean, Ocean Modelling, 20, 35-60, doi:10.1016/j.ocemod.2007.07.001, 2008c.

Ardhuin, F., Marie, L., Rascle, N., Forget, P., and Roland, A.: Observation and estimation of Lagrangian Stokes and Eulerian currents induced by wind at the sea surface, J. Phys. Oceanogr., 39, 2820-2838, 2009.

Ardhuin, F., Rogers, E., Babanin, A. V., Filipot, J., Magne, R., Roland, A., van der Westhuysen, A., Queffeulou, P., Lefevre, J., Aouf, L., and Collard, F.: Semiempirical Dissipation Source Functions for Ocean Waves. Part I: Definition, Calibration, and Validation, J. Phys. Oceanogr., 40, 1917-1941, doi:10.1175/2010JPO4324.1, 2010.

Bennis, A. and Ardhuin, F.: Comments on "The Depth-Dependent current and Wave Interaction Equations: A Revision”, J. Phys. Oceanogr., 41, 2008-2012, 2011.

Bennis, A., Ardhuin, F., and Dumas, F.: On the coupling of wave and three-dimensional circulation models: Choice of theoretical framework, pratical implementation and adiabatic tests, Ocean Model., 40, 260-272, 2011.
Berné, S., Satra, C., Alosi, J., Baztan, J., Dennielou, B., Droz, L., Reis, A. D., Lofi, J., Méar, Y., and Rabineau, M.: Carte morpho-bathymétrique du Golfe du Lion, notice explicative. Institut français de recherche pour l'éléxploitation de la mer (IFREMER), Brest, France, 2002.

Blumberg, A. and Mellor, G.: A description of a three-dimensional coastal ocean circulation model, Three-dimensional Coastal Ocean Models, Coastal and Estuarine Sciences, American Geophysical Union, 4, 1-16, 1987.

Booij, N., Ris, R., and Holthuijsen, L.: A third generation wave model for coastal regions, part1: model descritpion and validation, J. Geophys. Res., 104, 7649-7666, 1999.

Bourrin, F., Friend, P., Amos, C., Manca, E., Ulses, C., Palanques, A., de Madron, X. D., and Thompson, C.: Sediment dispersal from a typical Mediterranean flood: The Têt River, Gulf of Lions, Cont. Shelf Res., 28, 1895-1910, doi:10.1016/j.csr.2008.06.005, 2008.

Bowen, A.: Rip currents: 1.Theoretical investigations, J. Geophys. Res., 74, 5467-5478, 1969.

Bruneau, N.: Modélisation morphodynamique des plages sableuses, Ph.D. thesis, Université Bordeaux I, 2009.

Burchard, H. and Bolding, K.: Comparative analysis of four secondmoment turbulence closure models for the oceanic mixed layer, J. Phys. Oceanogr., 31, 1943-1968, 2001.

Certain, R.: Morphodynamique d'une côte sableuse microtidale à barres : le Golfe du Lion (Languedoc-Roussillon), Ph.D. thesis, Université de Perpignan, 2002.

Chawla, A. and Kirby, J.: Monochromatic and random wave breaking at blocking points, J. Geophys. Res., 107, C7, doi:10.1029/2001JC001042, 2002.

Chen, Q., Kirby, J. T., Dalrymple, R. A., Fengyan, S., and Thornton, E. B.: Boussinesq modeling of longshore currents, J. Geophys. Res. Oceans, 108, 1-24, 2003.

Clark, D., Feddersen, F., and Guza, R.: Boussinesq modeling of surfzone tracer plumes, part 2: Tracer plumes and cross-shore dispersion, J. Geophys. Res., 116, C11028, doi:10.1029/2011JC007211, 2011.

Craig, P. D. and Banner, M. L.: Modeling Wave-Enhanced Turbulence in the Ocean Surface Layer, J. Phys. Oceanogr., 24, 25462559, 1994.

Davies, A. and Jones, J.: Sensitivity of tidal bed stress distributions, near bed currents, overtides and tidal residuals to frictional effect in the eastern Irish Sea, J. Phys. Oceanogr., 26, 2553-2575, 1996.

Delpey, M. T., Ardhuin, F., Collard, F., and Chapron, B.: Space-time structure of long ocean swell fields, J. Geophys. Res.-Oceans, 115, C12037, doi:10.1029/2009JC005885, 2010.

Delpont, G. and Motti, E.: Monitoring by remote sensing of the geomorphological evolution of a part of the Roussillon coastal layout (France), Oceanis 94 Osates, pp. 44-47, 1994.

Donelan, M., Dobson, F., and Smith, S.: On the dependance of sea surface roughness on wave development, J. Phys. Oceanogr., 23 , 2143-2149, 1993.

Dufois, F.: Modélisation du transport particulaire dans le Golfe du Lion en vue d'une application au devenir des traceurs radioactifs issus du Rhône, Ph.D. thesis, Université du Sud Toulon-Var, 2008

Estournel, C. and Guedalia, D.: A new parameterization of eddy diffusivities for nocturnal boundary-layer modelling, Bound.-Lay. Meteorol., 39, 191-203, 1987. 
Estournel, C., Broche, P., Marsaleix, P., Devenon, J., Auclair, F., and Vehil, R.: The Rhone river plume in unsteady conditions: Numerical and experimental results, Estuarine Coast. Shelf Sci., 53, 25-38, 2001.

Estournel, C., Durrieu de Madron, X., Marsaleix, P., Auclair, F., Julliand, C., and Vehil, R.: Observation and modeling of the winter coastal oceanic circulation in the Gulf of Lion under wind conditions influenced by the continental orography (FETCH experiment), J. Geophys. Res.-Oceans, 108, 8059, doi:10.1029/2001JC000825, 2003.

Estournel, C., Zervakis, V., Marsaleix, P., Papadopoulos, A., Auclair, F., Perivoliotis, L., and Tragou, E.: Dense water formation and cascading in the Gulf of Thermaikos (North Aegean), from observations and modelling, Cont. Shelf Res., 25, 2366-2386, doi:10.1016/j.csr.2005.08.014, 2005.

Estournel, C., Auclair, F., Lux, M., Nguyen, C., and Marsaleix, P.: "Scale oriented" embedded modeling of the North-Western Mediterranean in the frame of MFSTEP, Ocean Sci., 5, 73-90, doi:10.5194/os-5-73-2009, 2009.

Flather, R.: A tidal model of the northwest european continental shelf, Mémoires, Société Royale des Sciences de Liege 6, 10, 141-164, 1976.

Galperin, B., Kantha, L., Hassid, S., and Rosati, A.: A quasiequilibrium turbulent energy model for geophysical flows, J. Atmos. Sci., 45, 55-62, 1988.

Garrett, C.: Generation of Langmuir circulations by surface waves - a feedback mechanism, J. Mar. Res., 34, 117-130, 1976.

Guillén, J., Bourrin, F., Palanques, A., de Madron, X. D., Puig, P., and Buscail, R.: Sediment dynamics during wet and dry storm events on the Têt inner shelf (SW Gulf of Lions), Marine Geology, 234, 129-142, 2006.

Guizien, K.: Spatial variability of wave conditions in the Gulf of Lions (NW Mediterranean Sea), Vie et milieu, 59, 261-270, 2009.

Haas, K. A. and Svendsen, I. A.: Laboratory measurements of the vertical structure of rip currents, J. Geophys. Res., 107, C5, doi:10.1029/2001JC000911, 2002

Haas, K. A. and Warner, J. C.: Comparing a quasi-3D to a full 3D nearshore circulation model: SHORECIRC and ROMS, Ocean Model., 26, 91-103, 2009.

Haas, K. A., Svendsen, I. A., Haller, M., and Zhao, Q.: Quasi-threedimensional modeling of rip current systems, J. Geophys. Res., 108, 3217, doi:10.1029/2002JC001355, 2003.

Haller, M., Dalrymple, R., and Svendsen, I. A.: Experimental study of nearshore dynamics on a barred beach with rip channels, J. Geophys. Res., 107, C6, doi:10.1029/2001JC000955, 2002.

Jenkins, A. D.: The use of a wave prediction model for driving a near-surface current model, Deut. Hydrogr. Z, 42, 133-149, 1989.

Jordà, G., Bolaños, R., Espino, M., and Sánchez-Arcilla, A.: Assessment of the importance of the current-wave coupling in the shelf ocean forecasts, Ocean Sci., 3, 345-362, doi:10.5194/os-3345-2007, 2007.

Kantha, L. and Clayson, C.: An improved mixed layer model for geophysical applications, J. Geophys. Res., 99, 25235-25266, 1994.

Komar, P., Neudeck, R., and Kulm, L.: Shelf Sediment Transport, chap. Observations and significance of deep-water oscillatory ripple marks on the Oregon continental shelf, Hutchinson and Ross, Stroudsburg, Pa, 1972.
Kumar, N., Voulgaris, G., and Warner, J.: Implementation and modification of a three-dimensional radiation stress formulation for surf zone and rip-current applications, Coastal Engineering, 58, 1097-1117, 2011.

Lazure, P. and Dumas, F.: An external-internal mode coupling for 3D hydrodynamical model for applications at regional scale (MARS), Adv. Water Resour., 31, 233-250, 2008.

Lentz, S. J., Guza, R. T., Elgar, S., Feddersen, F., and Herbers, T. H. C.: Momentum balances on the North Carolina inner shelf, J. Geophys. Res., 104, 18205-18226, 1999.

Lentz, S. J., Fewings, M., Howd, P., Fredericks, J., and Hathaway, K.: Observations and a Model of Undertow over the Inner Continental Shelf, J. Phys. Oceanogr., 38, 2341-2357, 2008.

Leredde, Y. and Michaud, H.: Hydrodynamique sédimentaire sur le plateau continental du Golfe du Lion, in: Xèmes Journées Nationales Génie Cotier-Génie Civil, 14-16 octobre 2008, SophiaAntipolis, pp. 111-123, 2008.

Longuet-Higgins, M. and Stewart, R.: Radiation stress and mass transport in gravity waves with application to surf beat, J. Fluid Mech., 13, 481-504, 1962.

MacMahan, J., Thornton, E., Stanton, T., and Reniers, A.: RIPEX: Observations of a rip current system, Mar. Geol., 218, 113-134, 2005.

Madec, G.: NEMO ocean engine, Note du Pole de modelisation, Institut Pierre-Simon Laplace (IPSL), France, no 27, 2008.

Marsaleix, P., Auclair, F., and Estournel, C.: Considerations on open boundary conditions for regional and coastal ocean models., J. Atmos. Oceanic Technol., 23, 1604-1613, doi:10.1175/JTECH1930.1, 2006.

Marsaleix, P., Auclair, F., Floor, J. W., Herrmann, M. J., Estournel, C., Pairaud, I., and Ulses, C.: Energy conservation issues in sigma-coordinate free-surface ocean models, Ocean Model., 20, 61-89, doi:10.1016/j.ocemod.2007.07.005, 2008.

Marsaleix, P., Auclair, F., and Estournel, C.: Low-order pressure gradient schemes in sigma coordinate models: The seamount test revisited, Ocean Modelling, 30, 169-177, 2009a.

Marsaleix, P., Ulses, C., Pairaud, I., Herrmann, M. J., Floor, J. W., Estournel, C., and Auclair, F.: Open boundary conditions for internal gravity wave modelling using polarization relations, Ocean Model., 29, 27-42, 2009b.

Mastenbroek, C., Burgers, G., and Janssen, P.: The dynamical coupling of a wave model and a storm surge model through the atmospheric boundary layer, J. Phys. Oceanogr., 23, 1856-1866, 1993.

McWilliams, J. C., Restrepo, J. M., and Lane, E. M.: An asymptotic theory for the interaction of waves and currents in coastal waters, J. Fluid Mech., 511, 135-178, doi:10.1017/S0022112004009358, 2004.

Mellor, G.: The Three-Dimensional current and surface wave equations, J. Phys. Oceanogr., 33, 1978-1989, 2003.

Michaud, H., Leredde, Y., Estournel, C., Berthebaud, E., and Marsaleix, P.: Hydrodynamics during a typical winter storm in the Gulf of Aigues-Mortes (NW Mediterranean Sea): In-situ measurements and numerical modelling, Comptes Rendus Geoscience, submitted, 2012.

Myrhaug, D., Holmedal, L. E., Simons, R. R., and MacIver, R. D.: Bottom friction in random waves plus current flow, Coastal Engineering, 43, 75-92, 2001. 
Newberger, P. and Allen, J.: Forcing a three-dimensional, hydrostatic, primitive-equation model for application in the surf zone: 1. Formulation, J. Geophys. Res., 112, C08018, doi:10.1029/2006JC003472, 2007.

Palanques, A., Puig, P., Guillén, J., Durrieu de Madron, X., Latasa, M., Scharek, R., and Martin, J.: Effects of storm events on the shelf-to-basin sediment transport in the southwestern end of the Gulf of Lions (Northwestern Mediterranean), Nat. Hazards Earth Syst. Sci., 11, 843-850, doi:10.5194/nhess-11-843-2011, 2011.

Phillips, O.: The dynamics of the upper ocean, Cambridge University Press, London, 1977.

Rascle, N.: Impact des vagues sur la circulation océanique, Ph.D. thesis, Université de Bretagne Occidentale, 2007.

Rascle, N. and Ardhuin, F.: Drift and mixing under the ocean surface revisited: Stratified conditions and model-data comparisons, J. Geophys. Res., 114, C02016, doi:10.1029/2007JC004466, 2009.

Rascle, N., Ardhuin, F., and Terray, E. A.: Drift and mixing under the ocean surface: A coherent one-dimensional description with application to unstratified conditions, J. Geophys. Res., 111, C03016, doi:10.1029/2005JC003004, 2006.

Rascle, N., Ardhuin, F., Queffeulou, P., and Croizé-Fillon, D.: A global wave parameter database for geophysical applications. Part I: Wave-current-turbulence interaction parameters for the open ocean based on traditional parameterizations, Ocean Model., 25, 154-171, 2008.

Reniers, A., Symonds, G., and Thornton, E.: Modelling of rip currents during rdex, in: Coastal Dynamics '01: Proceedings, edited by Hanson, H and Larson, M, pp. 493-499, Amer Soc Civil Engineers, Coasts, Oceans, Ports \& Rivers Inst, 4th International Conference on Coastal Dynamics, Lund, Sweden, 11-15 June 2001, 2001.

Reniers, A., Roelvink, J., and Thornton, E.: Morphodynamic modeling of an embayed beach under wave group forcing, J. Geophys. Res., 109, C01030, doi:10.1029/2002JC001586, 2004.

Rusu, E. and Soares, C. G.: Numerical modelling to estimate the spatial distribution of the wave energy in the Portuguese nearshore, Renewable Energy, 34, 1501-1516, 2009.

Serrat, P., Ludwig, W., Navarro, B., and Blazi, J.: Variabilité spatiotemporelle des flux de maières en suspension d'un fleuve côtier méditerranéen: la Têt (France), Comptes Rendus de l'Académie des Sciences, D333, 389-397, 2001.

Shchepetkin, A. and McWilliams, J.: The regional oceanic modeling system (ROMS): a split-explicit, free-surface, topographyfollowing-coordinate oceanic model, Ocean Model., 9, 347-404, doi:10.1016/j.ocemod.2004.08.002, 2005.

Smith, J. A.: Wave-current interactions in finite-depth, J. Phys. Oceanogr., 36, 1403-1419, 2006.

Smith, R.: Reflection of short gravity waves on a non-uniform current, Math. Proc. Cambridge Philos. Soc., 78, 517-525, 1975.

Soulsby, R., Stive, M., de Vriend, H., Fredsoe, J., Hamm, L., Teisson, C., and Winterwerp, J.: Bed shear stresses due to combined waves and current, Adv. Coastal Morphodynamics, 4-20, 4-23, 1995.

Stokes, G.: On the theory of oscillatory waves, Transactions of the Cambridge Philosophical Society, 8, 441-455, 1847.

Svendsen, I. A., Haas, K., and Zhao, Q.: Shorecirc - the quasi3d nearshore circulation model., Tech. Rep. Technical report CACR-02-01, University of Delaware, Center for Applied
Coastal Research, 2002.

Taylor, G.: Standing waves on a contracting or expanding current, J. Fluid Mech., 13, 182-194, 1962.

Terray, E. A., Donelan, M., Agrawal, Y., Drennan, W., Kahma, K., Williams, A., Hwang, P., and Kitaigorodskii, S.: Estimates of kinetic energy dissipation under breaking waves, J. Physical Oceanogr., 26, 792-807, 1996.

Terray, E. A., Drennan, W., and Donelan, M.: The vertical structure of shear and dissipation in the ocean surface layer, Proc. Symp. on Air-Sea Interaction, pp. 239-245, 2000.

Tolman, H.: A mosaic approach to wind wave modeling, Ocean Model., 25, 35-47, doi:10.1016/j.ocemod.2008.06.005, 2008.

Tolman, H.: User Manual and system documentation of WAVEWATCH-III version 3.14. Technical Report, Tech. Rep. 276, NOAA/NWS/NCEP/MMAB, 2009.

Tonani, M., Pinardi, N., Dobricic, S., Pujol, I., and Fratianni, C.: A high-resolution free-surface model of the Mediterranean Sea, Ocean Sci., 4, 1-14, doi:10.5194/os-4-1-2008, 2008.

Trampenau, T., Oumeraci, H., and Dette, H.: Hydraulic functioning of permeable pile groins, J. Coastal Res., 33, 160-187, 2004.

Uchiyama, Y., McWilliams, J. C., and Shchepetkin, A. F.: Wave-current interaction in an oceanic circulation model with a vortex-force formalism: Application to the surf zone, Ocean Model., 34, 16-35, doi:10.1016/j.ocemod.2010.04.002, 2010.

Ulses, C.: Dynamique océanique et transport de la matière particulaire dans le Golfe du Lion: Crue, tempête et période hivernale, Ph.D. thesis, Université Paul Sabatier Toulouse, 2005.

Ulses, C., Estournel, C., Bonnin, J., Durrieu de Madron, X., and Marsaleix, P.: Impact of storms and dense water cascading on shelf-slope exchanges in the Gulf of Lion (NW Mediterranean), J. Geophys. Res., 113, C02010, doi:10.1029/2006JC003795, 2008a.

Ulses, C., Estournel, C., Durrieu de Madron, X., and Palanques, A.: Suspended sediment transport in the Gulf of Lions (NW Mediterranean): Impact of extreme storms and floods, Cont. Shelf Res., 28, 2048-2070, doi:10.1016/j.csr.2008.01.015, 2008b.

Ulses, C., Estournel, C., Puig, P., Durrieu de Madron, X. D., and Marsaleix, P.: Dense shelf water cascading in the northwestern Mediterranean during the cold winter 2005: Quantification of the export through the Gulf of Lion and the Catalan margin, Geophys. Res. Lett., 35, L07610, doi:10.1029/2008GL033257, 2008c.

Warner, J., Sherwood, C., Arango, H., and Signell, R. P.: Performance of four turbulence closure models implemented using a generic length scale method, Ocean Model., 8, 81-113, 2005.

Weaver, P., Canals, M., and Trincardi, F.: EUROSTRATAFORM Special Issue of Marine Geology, Marine Geology, 234, 1-2, doi:10.1016/j.margeo.2006.09.001, 2006.

Weir, B., Uchiyama, Y., Lane, E. M., Restrepo, J. M., and Williams, J. M.: A vortex force analysis of the interaction of rip currents and surface gravity waves, J. Geophys. Res., 116, C05001, doi:10.1029/2010JC006232, 2011.

Whitham, G.: Mass, momentum and energy flux in water waves, J. Fluid Mech., 12, 135-147, 1962.

$\mathrm{Xu}, \mathrm{Z}$. and Bowen, A.: Wave- and wind-driven flow in water of finite depth, J. Phys. Oceanogr., 24, 1850-1866, 1994.

Yu, J. and Slinn, D.: Effects of wave-current interaction on rip currents, J. Geophys. Res., 108, 3088, doi:10.1029/2001JC001105, 2003. 